\title{
STAGES IN THE ORIGIN OF VERTEBRATES: ANALYSIS BY MEANS OF SCENARIOS
}

\author{
BY CARI, GANS \\ Department of Biology, The University of Michigan, \\ Ann Arbor, MI 48 го9, U.S.A.
}

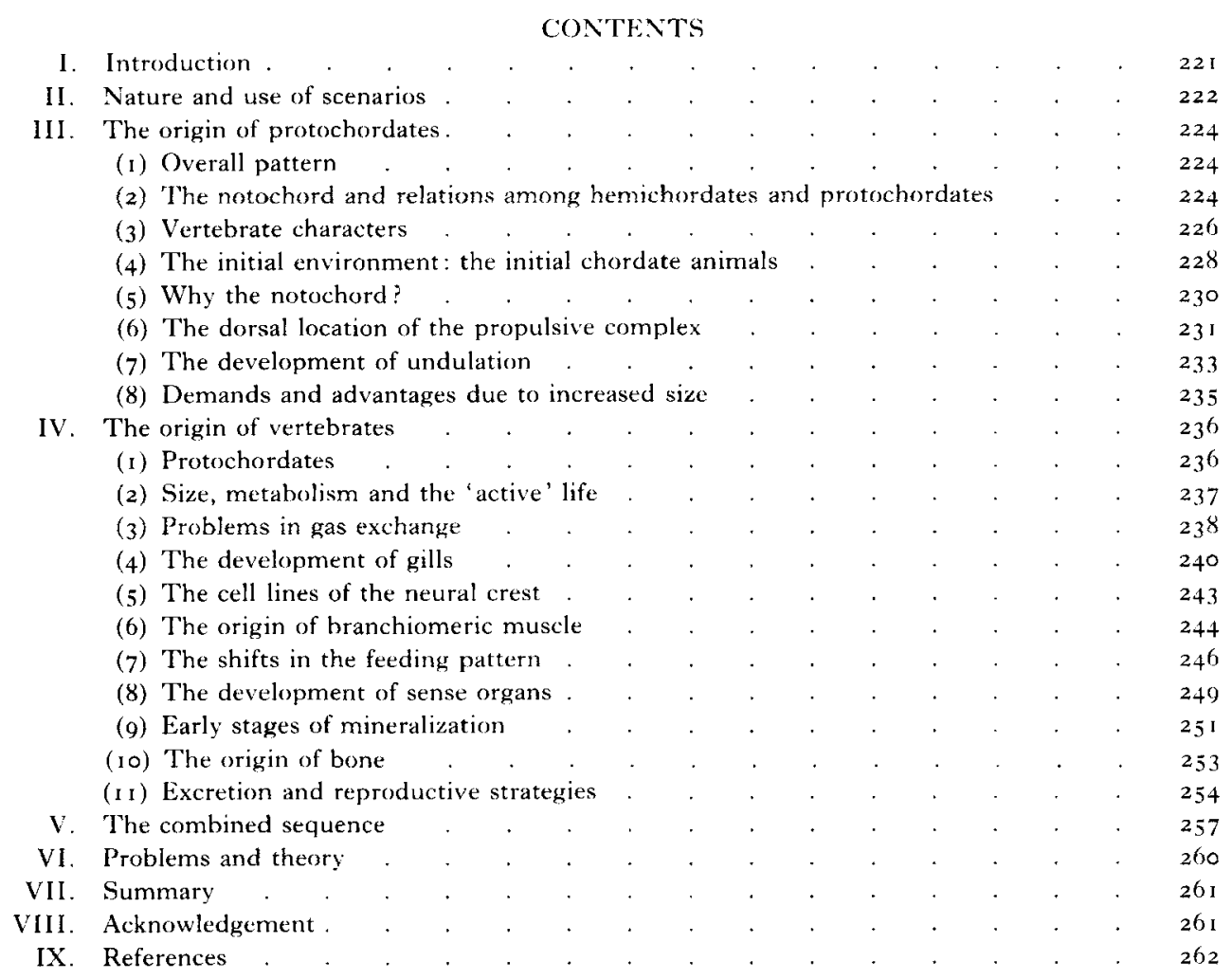

\section{INTRODUCTION}

Our knowledge of the earliest vertebrates depends primarily upon indeterminable bony remnants and more complete remains of relatively advanced jawless vertebrates (Romer, 1966; Moy-Thomas \& Miles, 197 I; Olson, I971 ; Jarvik, I980). These animals are not easy to derive from any surviving group of invertebrates; hence, the search for sister groups and possible ecological aspects of their evolution remains a regularly debated issue (Jollie, I97I, 1973; Lovtrup, I977; Jarvik, I980; Gutmann \& Bonik, I 98 I ; Mallatt, I 985 ; Jefferies, 1987 ).

It has recently been pointed out that the vertebrates are characterized uniquely by two embryonic tissues namely neural crest and neurogenic epidermal placodes, which give rise to practically all their shared-derived structures (synapomorphies) (Gans, 1985, I987; Gans \& Northcutt, 1983, 1985; Northcutt \& Gans, 1983, I984). The 
suggestion is that these synapomorphies are homologous to the deuterostome epidermal nerve plexus. Calcification was proposed to have developed late in the evolutionary transition from prevertebrates to vertebrates and only affected adult (postmetamorphic) animals, so that the neural crest and placodes were established before the first bony ostracoderms appear in the fossil record.

If this view is correct, it is unlikely that fossils documenting the transition will ever come to hand. 'This forces us to utilize scenarios to gain an understanding of the changes driving the transition. In view of the uncertainty of the procedure, alternatives for each of the several steps are listed and evaluated. Alternatives permit consideration of testable corollaries and refined understanding of the transition to vertebrates.

\section{NATURE ANID USE OF SCENARIOS}

Discussions of the 'origin' of structures and other major systems have traditionally relied on scenarios; these were often so broadly stated that they became vague and untestable. Recently, reaction has become fashionable, leading to the suggestion that phylogenetic scenarios are 'fairy tales' rather than a scientific endeavour (Eldredge \& Cracraft, 1980; but see Eldredge, I979; Kemp, 1982; (Jans, 1985).

Scenarios are here defined as 'outline(s) of a hypothesized chain of events' (Onions, I 955). Phylogenetic scenarios are viewed as representing a second set of evolutionary hypotheses complementing the primary cladograms, which provide the initial basis for analysis. Clearly, biology must be more than the testing of hypotheses about phylogenetic pattern; it must also test hypotheses about the historical process responsible for the observed phenotypes. Notation that some phenotypic aspect has been 'gained' or 'lost' between two phylogenetic stages does not do so. Characterization of the historical process demands understanding of the way ancient organisms interacted with the hiological, physical and chemical aspects of their environments.

Reconstruction of processes of change during evolutionary time is aided but not resolved by the fossil record. For instance, cladistics has long struggled with the methodology of placing fossils within cladograms primarily based upon extant species (Patterson \& Rosen, 1977); in contrast, fossils are the key subjects of phylogenetic scenarios. Furthermore, even the occurrence of numerous bony fossils does not, directly or simply, help the palaeontologist reconstruct the life-histories of the organisms that left these remains. At the very least there remains the problem of reconstructing the soft tissues.

Several basic rules let one establish scenarios. First, scenarios must derive from a phylogenetic scheme. Secondly, they should be based upon the best possible information about the biology of the extant members of the groups being considered. All scenarios here proposed are based on the acceptance of natural selection and adaptation as presently characterized and on the uniformitarian assumption that present mechanisms of ecology, behaviour, physiology and morphology operated previously; this assumption is set aside only if observations cannot be explained by the mechanisms occurring now. Proposers of phylogenetic scenarios resemble astronomers, who assume that the physical laws operating in our part of the universe also apply elsewhere and indeed applied there at the time that the stars generated the light that we perceive only now.

Any single phenotypic pattern may be derived by more than one adaptive pathway. 
Each hypothesis must then be framed in a way that permits evaluation of its relative merits. Critics of scenario generation are correct in noting that tests of events must proceed beyond their possibility to their relative probability. This should not imply that "nature always follows the most probable path" or that events most probable on mechanistic grounds are those most likely to have occurred in history. However, from an operational viewpoint, Occam's razor (methodological parsimony, cf. Kluge, i 984) seems an eminently suitable guide to scenario generation. Nevertheless, the intrinsic uncertainty generated by inadequate evidence inevitably affects the plausibility of results; both the immediate comparison and corollaries that result from the decision may require modification whenever new facts are uncovered. Hence, a range of potential scenarios (of different probabilities), rather than only a single one, may have to be accepted.

What kinds of tests are possible? As evolutionary events represent stages of history, they are lost in time and cannot be tested directly. Tests must be restricted to corollaries of the hypotheses. For any set of hypotheses, the corollaries should be internally consistent. Tests may result from examination of the structures of Recent animals and available fossils (and search for others) in order to establish whether their attributes fit the prediction. Even examination of Recent animals can be carried out with relatively little risk of circularity, as many biological phenomena remain to be examined in most living species and even in many major groups. For a specific example of this approach consider the evolutionary transition of the mechanism for ventilating the lung. It was proposed that pulse pumping changed to aspiration breathing in fishes and that the change was complete by the time of the earliest tetrapods (Gans, 1970). The alternative was that ancestral amphibians were pulse-pumpers and that aspiration breathing first occurred in the earliest reptiles. A corollary of the second hypothesis is that fossil amphibians should have had reduced ribs and an unarmoured (and vascularized) skin. Consequently, the occurrence of stout well-articulated ribs and dermal armour in fossil amphibians (Romer, I 966) falsifies the hypothesis that they were pulse pumpers (indeed it is concordant with the view that the rhipidistians presumably ancestral to them were aspiration breathers as well).

The formulation of phylogenetic scenarios forces us to look at organisms in new ways and to ask questions about systems that would otherwise be ignored. Hence, it emphasizes situations for which evidence as yet remains inadequate. The discussions that follow represent the results of a prolonged examination of 'known' facts, generation of possible scenarios, evaluation of their corollaries and search for additional information permitting re-evaluation of initial assumptions on vertebrate origins.

Developmental information allows another important set of tests. However, the development of non-vertebrate deuterostomes needs further study with modern techniques and protochordate ontogenies will probably continue to provide insight into the origin and evolution of chordates. Hence, developmental as well as functional corollaries are considered, whenever two or more evolutionary sequences are equally plausible.

The following discussion begins with a series of hypotheses about the origin of particular characters and functional processes. Generally, the effects of different transformations are interconnected. For example, any capacity for directed locomotion makes it more likely that attempts at predation on particular micro-organisms, rather 
than random suspension-feeding, would incur an advantage. Thus, even slight modification of one functional system would affect the likelihood that additional modifications would become advantageous in others. Obviously, some systems are likely to show strong and others weak interactions. Whereas it is impossible to deal with all such aspects simultaneously, the possibility of interaction and its differential effect involves a powerful additional level of hypotheses and tests.

\section{THE ORIGIN OF PRO'TOCHORDATES}

\section{(I) Overall pattern}

Any phylogenetic scenario must be based on a particular hypothesis of relationships of the organisms. An analysis of known deuterostome characters leads to the hypothesis of phyletic relationships illustrated in Fig. $\mathbf{I}$.

For this review, 'vertebrates' includes all craniates, and leaves aside the question of whether the agnathans are a truly monophyletic group (cf. Stensiö, I 968; Hardisty, I 979; Janvier \& Blieck, I979; Schaeffer \& Thomson, I980; Janvier, I981; Forey, I984; Mallatt, $1984 b$, I 985 ; Yalden, 1985). The term 'chordates' includes protochordates and vertebrates. The term 'protochordates' includes the urochordates plus cephalochordates and thus defines a paraphyletic grouping (Fig. 1).

'The terms 'prechordates' and 'prevertebrates' will be used here as idealizations in a non-systematic sense, representing precursors, respectively, of the animals here defined as the chordates and vertebrates. Thus, statements about anatomical arrangement in hemichordates, chordates, protochordates and vertebrates refer to actually observable character states. In contrast, those about prechordates or prevertebrates represent the best estimates of the anatomy and role in precursor organisms.

\section{(2) The notochord and relations among hemichordates and protochordates}

The cephalochordates are probably a sister group of the vertebrates, because their adults share the derived characters of a segmented muscular trunk and repetitive somites, a notochord, a dorsal hollow nerve cord, a post-anal tail, a ventral-to-dorsal circulation through the pharyngeal bars, and excretory tissue with podocytes (Drach, 1948; Romer, 1962; Barrington, 1965; Carter, 1971; Guthrie, 1975; Welsch, 1975; Northcutt \& (ians, 1983). In contrast, urochordates can only be considered as a sister group to the cephalochordate-vertebrate assemblage, with which they primitively share an atrial system and a notochord as larvae, but usually not as adults (Garstang, i 929; Berrill, 1950); although Godeaux (1974) suggests that the urochordate atrium is not homologous to the atrium of Branchiostoma. However, analysis of urochordate anatomy and development remains complicated as several groups are colonial and highly unusual (cf. Godeaux, 1957).

The hemichordates (enteropneusts and pterobranchs) are viewed as a likely sister group of the chordates. Their stomochord is not homologous to the notochord; rather it is confined to the proboscis, and not associated with the dorsal hollow nerve cord (or nerve plate of the collar) and the longitudinal muscles of the trunk. Also, at least Rhabdopleura among pterobranch urochordates lacks pharyngeal slits (Jollie, 1962). If this were primitive rather than secondary, it would imply a diphyletic origin of 


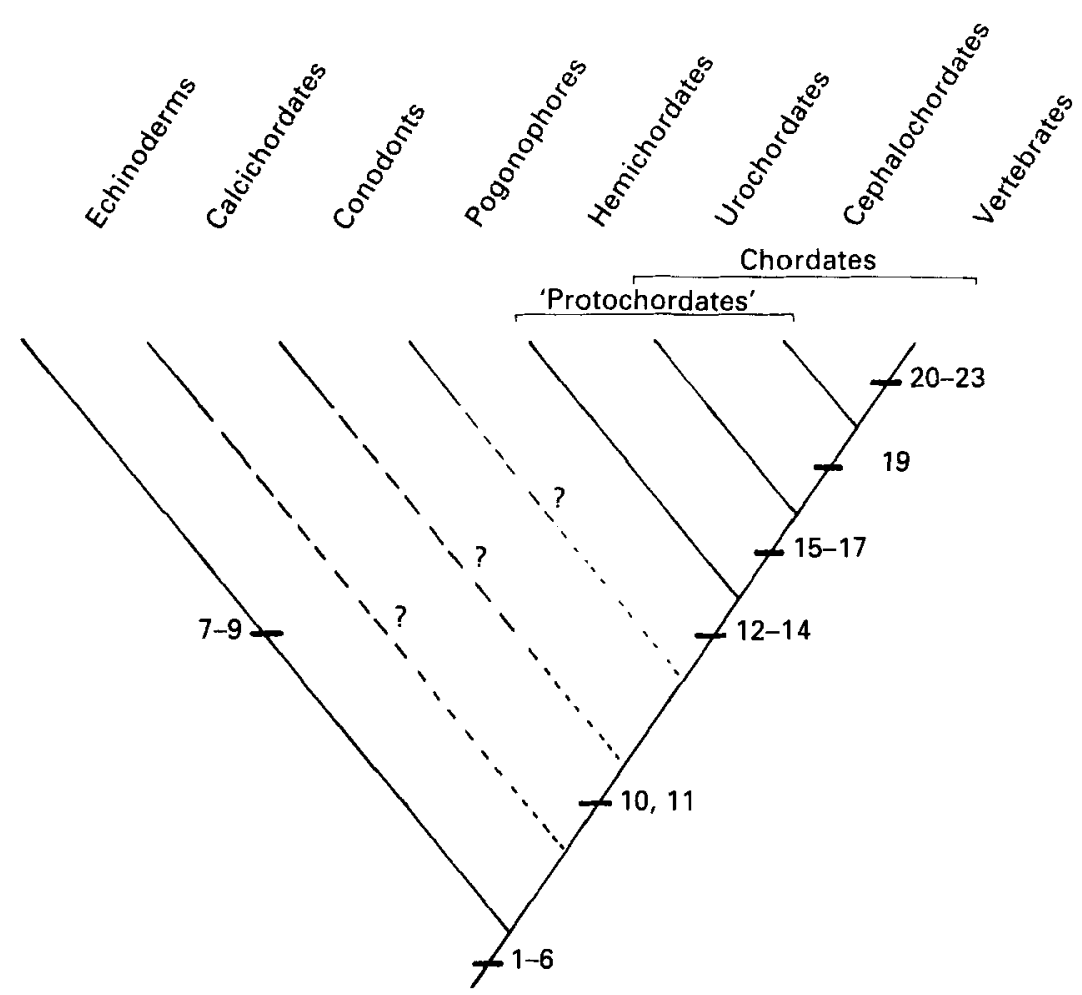

Fig. I. Cladogram of the major groups discussed with listing of the possible synapomorphies categorizing various deuterostomes. (1) Bilateral symmetrical larva with external ciliation. (2) Blastopore becomes larval anus or anus forms near blastopore. (3) Mouth forms at opposite pole to blastopore. (4) Epidermal nerve plexus present. (5) Mesoderm of enterocoelous origin. (6) Coelom tripartite. (7) Adults exhibit pentamerous radial symmetry. (8) Adults possess water-vascular system. (9) Excretory system absent. (IO) Adult exhibit bilateral symmetry. (II) Closed circulatory system. (12) Adult exhibit paired pharyngeal clefts. (i3) Head blood vessels interconnected by aortic arches. (14) Endostylar organ. (15) Notochord. (16) Dorsal hollow nerve cord. (17) Atrial system. (18) Body wall and post-anal tail possess segmented muscles. (19) Podocytes. (20) Neural crest. (21) Neurogenic epidermal placodes. (22) Muscular hypomere. (23) Calcified sclerotome.

pharyngeal slits, with less probability of closeness of the hemichordate-chordate association.

The 'notochord' of the several urochordate (tunicate) groups is generally assumed to be homologous. However, in two of the three groups of urochordates (ascidians and thaliaceans) it is restricted to the larval stage and only two of the three groups (ascidians and larvaceans, but not thaliaceans) use it in locomotion (Brien, 1948; Barnes, I966; Braconnot, 1970; Godeaux, 1974). Urochordates also pose other problems. Each subgroup has a distinct locomotor system, the only common denominator being a notochord restricted to the posterior portion of the animal at some time during development (Brien, I948). The ascidian larvae move by bursts of undulation; at metamorphosis they become sessile and develop an external tunic. The larvaceans have ten muscle cells on each side of the notochord. The thaliaceans move by contractions of their barrel-shaped body effected by the circumferential muscles in a pattern that does not involve a notochord (Brien, I 948). 
Some obvious questions arise about the homology of the caudal urochordate notochord, and the claimed homology of the caudal muscles of larval ascidians with the somites or myotomes of other chordates. The greatest difficulty in using morphological evidence for decisions about these homologies is the question of size. Larval ascidians are less than $2 \mathrm{~mm}$ long; their caudal muscles consist of three or four rows of serially arranged cells and a notochord, filled with large vacuolated cells, in a sheath of connective tissue fibres; the diameter of the notochord is barely larger than that of a single cell (Katz, I983). It would be useful to re-examine the classical data on urochordate immunological affinities and biochemical pathways (cf. Kerkut, I960; Watts, 1975; Lovtrup, 1977) and to supplement them with more modern approaches.

In this analysis, urochordate muscles and notochord are assumed to be homologues of the equivalently named structures in the cephalochordate-vertebrate assemblage, i.e. many larval urochordate characters represent the retention of a more primitive state, rather than reductions from that of cephalochordates. Therefore urochordates are treated as a sister group of the cephalochordate-vertebrate assemblage. The hemichordates (at least the enteropneusts) then would be considered a sister group of the chordates, based upon the presence of a three-part coelom, pharyngeal slits and perhaps aortic arches (cf. Goodrich 1917; Young, 198I). The contrary view, that the urochordate notochord is a homoplasious structure, would leave the phylogenetic relationships of urochordates, hemichordates and chordates unresolved.

There are alternative hypotheses about vertebrate affinities. Historically, several other taxa have been offered as the sister group of vertebrates. Among these are pogonophorans (Ivanov, 1963; but see Southward, 1975), nemerteans (Jensen, I963; Willmer, 1974, 1975; but see Gibson, 1972), urochordates (Kowalewski, 1866; Darwin, I 871 ; Garstang, 1929; Berrill, 1950; Whitear, 1957; Romer, I962; Jollie, I971, I973; Katz, 1983) and even annelids and arachnids (Gaskell, 1908; Patten, 1912) and molluscs (Løvtrup, 1977). However, all these comparisons emphasize what is here interpreted as shared primitive rather than derived characters. Similar difficulties occur in derivation from two fossil groups, calcichordates (Jefferies, 1987, and citations therein; but see Jollie, 1982; Gans, I 988) and conodonts (recently assumed to be early vertebrates Briggs, Clarkson \& Aldridge, I 983 ; Aldridge et al., 1986). Indeed, no character considered here to be derived uniquely associates any of these groups and vertebrates.

\section{(3) Vertebrate characters}

Whatever the variations of the phylogeny at the protochordate level, the structural pattern exhibited by cephalochordates (Acraniata) remains impressive. This pattern provides an ideal precursor for the vertebrate state (Craniata), differing mainly in the substantial number of vertebrate autapomorphies originating from embryonic neural crest and neurogenic epidermal placodes, and in the muscularization of the splanchnic lateral-plate mesoderm (hypomere; Table I, Fig. I, items 20-23). This suggests that cephalochordates and vertebrates are sister groups.

There is an obvious similarity between the muscularized epimeric tissues of vertebrates and other chordates. In contrast, neural crest and epidermal neurogenic placodes are unique to vertebrates. Urochordates and cephalochordates lack obvious homologues for these tissues. However, these groups do retain the deuterostome epidermal nerve plexus and it has been proposed that the plexus is homologous to such 


\section{Table I. Shared-derived characters of vertebrates*}

Embryonic

origin

Function

Nervous system

Sensory nerves with ganglia -- cranial

Sensory nerves with ganglia - trunk

Peripheral motor ganglia

Second- and higher-order motor neurons

Forebrain

Chromatophores

Paired special sense organs

Nose

Eyes (accessory organs)

Ears

Lateral-line mechanoreceptors

Lateral-line electroreceptors

Gustatory organs

Pharyngeal and alimentary modifications

Cartilaginous bars

Branchiomeric muscle

Smooth muscle of gut

Calcitonin cells

Chromaffin cells-Adrenal cortex

Circulatory system

Gill capillaries, endothelium

Major vessels, trunk

Wall of aortic arches

Muscular heart

Skeletal system

Anterior neurocranium and sensory capsules

Cephalic armour and derivatives

$\mathrm{NC} \quad \mathrm{P}-$

$\mathrm{NC} \quad-\quad-$

$\mathrm{NC} \quad-\quad-\cdots$

$\mathrm{NC} \quad-$

NC? - -

$\mathrm{NC}--$

G DI

- DI

G -- $\mathrm{p}$

$\mathrm{G}-\mathrm{P}$

- DI -

-- DI -

$-\quad \mathrm{P}-\quad-$ DI -

$\mathrm{NC} ? \quad(\mathrm{P})-\mathrm{DI}-$

$-\quad \mathrm{P}-\mathrm{P}-\mathrm{DI}$

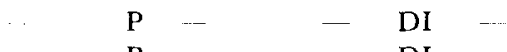

- P - $\quad$ P DI -

NC? $\mathrm{P}-\mathrm{Dl}-$

$\mathrm{NC} \quad-\quad-\quad \mathrm{G}-$

- $-\mathrm{ME}$ G DI P

$-\quad-\mathrm{MH} \quad-\quad-\quad \mathrm{P}$

$\mathrm{NC}-\quad-\quad-D I \quad P$

$\mathrm{NC} \quad-\ldots$ G $\quad$ DI $P$

$\begin{array}{llllll}- & - & \mathrm{ME} & \mathrm{G} & - & - \\ - & - & \mathrm{M} & \mathrm{G} & - & - \\ \mathrm{NC} & - & - & \mathrm{G} & - & - \\ - & -\ldots & \mathrm{MH} & \mathrm{G} & - & \ldots\end{array}$

$\mathrm{NC}--\quad-\mathrm{DI} P$

$\mathrm{NC} \quad-\quad-\ldots$ DI -

Armour of trunk

NC?? - ME? - DI -

\section{CODES}

Embryonic origin NC Neural crest

NC? Mixed outgrowth, intermediate between neurectoderm and neural crest

NC?? The nature of the various trunk armours remains uncertain

P Placodes

(P) Placodes provide lens and peripheral components, not sensory tissues

M Mesoderm

MH Mesoderm, Hypomere

ME Mesoderm, Epimere

Function

$\begin{array}{ll}\text { G } & \text { Gas exchange } \\ \text { DI } & \text { Food, detection and ingestion } \\ \text { P } & \text { Food, internal processing }\end{array}$

* Table modified after Northcutt \& Gans (1983). 
synapomorphies of vertebrates as supportive (cartilage, bone, dentine), muscular, and neural elements (see Northcutt \& Gans, 1983, and Le Douarin, 1982, for recent reviews).

The neural crest and placodal tissues share substantial similarities, although the analysis suggests that neither is a precursor of the other (Northcutt \& Gans, I983). The question remains whether (hypothesis I) the supportive, muscular and neural derivatives of these tissues represent independent inventions which later became associated, or (hypothesis 2) the tissues deriving from neural crest and placodes have a single phylogenetic origin.

The second hypothesis appears more plausible. The skeleton of protochordates lacks mineralization and is restricted to the notochord, myosepta, tunic and median fin rays (Brien, 1948; Barrington, 1965); this suggests that neural tissues (see throughout deuterostomes) are older than mineralized tissues. Previously provided evidence (Northcutt \& Gans, I983) documents that the epidermal nerve plexus of early deuterostomes gave rise to most of the shared-derived tissues of vertebrates. If this reasoning proves valid, it is important to explain how neurogenic tissues became associated with the muscles, and also with the skeletogenic and supportive tissues characterizing vertebrates.

\section{(4) The initial environment: the initial chordate animals}

Hypotheses about the origin of chordates demand consideration of the life-history of the ancestral stock in the context of the ancestral environment.

The environment was aqueous and probably marine, because the fossil record neither shows a terrestrial fauna nor a flora before the Silurian; whereas the first vertebrates may appear earlier in Cambrian strata (Romer, I 966; Olson, I971; Taylor, I98I). It is also unlikely that the initial chordates lived in fresh water, as there is no fossil record of any freshwater metazoans until the Silurian. Surviving non-vertebrate deuterostomes are marine (e.g. echinoderms, hemichordates, urochordates and cephalochordates), making a marine origin overwhelmingly convincing; to argue otherwise forces us to posit numerous independent re-invasions of a marine environment.

Metamorphosis is defined as a change in life-history, usually associated with a very drastic $m$ 'sphological shift often paralleled by maturation of the gonads (Just, KrausJust \& Check, I98I). It is probable that the earliest deuterostomes and ancestral chordates had a life-history that included freely moving larval stages that underwent a single or a double metamorphosis. The primary non-feeding larvae of cephalochordates have ciliated epithelia (Nielsen, 1987), and their first metamorphosis may be defined by virtue of the development of a notochord. In this case the doubling of pharyngeal slits and closure of the atrium of Branchiostoma represents a second metamorphosis leading to gonadal maturation at the start of the third period (Barrington, 1965).

Discussion of metamorphosis leads to considerations of motility. It is likely that at least the late larvae and possibly adults of ancestral prechordate organisms were ciliated internally and externally. This is the case for some larvae of the major groups of Recent deuterostomes (ascidians being an exception), as well as for those of some vertebrates (Brien, I 948; Whiting \& Bone, r 980 ; Nielsen, I987) and also for adult pogonophorans and hemichordates (Ivanov, I963; Nielsen, 1987). To assume differently would demand an independent origin of external ciliation in several lines. 
The widespread occurrence of ciliated epithelial surfaces in Recent deuterostomes is correlated with feeding and locomotion. Generally there are particle-entrapment mechanisms involving the cilia-mediated transport of water streams and mucus layers over the surface of the body. In some forms this leads to the passage of the water past tentacles or through internal chambers, covered or strung with mucus threads, so that particle extraction involves filtration, i.e. suspension feeding (Denison, 1961; Barrington, 1965; Mallatt, 1981; Gilmour, 1982; Strathmann, 1982).

Cephalochordates and some anamniotes have early ciliated stages with later muscular propulsion (Whiting \& Bone, r 980 ; Kemp, 1987). The larvae of some urochordates are initially ciliated (Brien, 1948). Others immediately develop a notochord and muscular propulsion, swimming by undulation. If late larvae or adults of some ancestral chordates had a notochord and undulated, the habitus of their adults remains a question. A first hypothesis suggests that they were sessile (Berrill, I955; Romer, I 962, 1972); but a second assumes that they were motile, using muscular deformations of a hydrostatically stiffened trunk (Bone, I960 $a$; Jollie, I977; Northcutt \& Gans, I983; Mallatt, $1984 b$ ). The three surviving lines of urochordates differ in their structural patterns and include both sessile and mobile forms. Cephalochordates are mobile (J. E. Webb, I973) and vertebrates even more so.

Historically, arguments about motility have been based on the living members of the obvious outgroup, the echinoderms, rather than on the locomotor pattern within the hemichordate-chordate group itself (Berrill, 1955; Romer, 1972). The assumption was that ancestral deuterostomes were probably sessile and this assumption extended to ancestral chordates as well. The sessile adult stage of these animals was supposedly lost, and the notochordal skeleton, presumably involved in propulsion, was retained into the adult stage as a novel adaptation. Hence, the sessile adult ascidians appeared to display the ancestral condition. However, ascidians are the only urochordates that have sessile adults, opening the strong possibility that the sessile condition of adult tunicates is not ancestral but secondary (Bone, $1960 b$ ). This is supported by the observation that pterobranchs and ascidian tunicates attach to the substrate with different parts of the body (Eaton, 1970).

Whatever the phyletic affinities of the calcichordates, all interpretations of their anatomical organization have been consistent with their presumed motility (Jefferies, 1987). If the ancestral deuterostomes were indeed sessile, transition to adult mobility must have occurred very early in deuterostome evolution. If they were sessile, mobility must have evolved independently at least once in echinoderms (Asteroidea, Echinoidea, Commatulidea), and perhaps as many as three times among chordates and their allies (hemichordates, urochordates, cephalochordates) (Barnes, I966). In contrast, the hypothesis that ancestral adult deuterostomes were mobile only requires the independent loss of mobility in some echinoderms and in one group each of hemichordates and urochordates. Hemichordates have a condensed peripheral nerve plexus and more central neural cords (Knight-Jones, 1952) and many urochordates show unpaired peripheral sense organs (Berrill, I950; Brien, I948). Such neural condensation and elaboration of peripheral sense organs otherwise are seen only in animals, such as cephalopods, molluscs, jellyfish and arthropods, that move about freely (Bullock \& Horridge, I965). Thus, it requires the fewest assumptions to consider the earliest adult chordates to have been mobile. 
This lets one model the condition of these earliest chordates as marine animals with ciliated suspension-feeding larvae. Primary metamorphosis transformed them into motile organisms with a notochord, a dorsal hollow nerve cord and muscle-powered propulsion. A second metamorphosis may have occurred at the time of gonadal maturation. What was the prechordate habitat and mode of life-history; specifically, what was the locomotor pattern of the adults? Critical to any answer is the question of why a notochord had developed in the first place.

\section{(5) Why the notochord?}

The notochord is a turgid tube, solidly filled with vacuolated cells and constrained by a collagenous covering, that maintains its shape as the internal pressure rises during bending; it is intrinsically a stiffening device (Clark, 1964; Ax \& Ax, 1969; Gutmann $\&$ Bonik, $198 \mathrm{I}$ ) and permits an ovoid animal to remain elongated without the maintenance of a series of separated coelomic cavities. The notochord also maintains the shape of animals lacking circumferential muscles. Notochords or hydrostatic chambers are found in the anterior end of hemichordates, in the 'tail' of urochordates, and extend along the body of cephalochordates and vertebrates.

There are four possible hypotheses about the site at which the notochord originated. (I) The notochord arose in the anterior region (as in hemichordates and perhaps nemertines; Willmer, 1974) and from here extended caudally into trunk and tail. (2) It shifted anteriorly from an origin in the posterior trunk or tail (as in urochordates). (3) It shifted both rostrally and caudally from an origin in the trunk. (4) It developed simultaneously along the dorsal surface of trunk and tail (as appears to occur in cephalochordates and vertebrates).

Development shows only two patterns. In the hemichordates, the notochord develops as an endodermal evagination of the anterior gut (Barrington, 1965); in urochordates, cephalochordates and most vertebrates, the notochord utilizes mesodermal materials derived from the roof of the archenteron (Brien, I 948 ; Balinsky, I98 I ; the report that the axolotl produces an ectodermal notochord confuses this issue, $\mathrm{cf}$. Brun \& Garson, 1984).

Functionally, the origin of a notochord is associated with stiffening of the trunk, assisting burrowing or maintenance of pharyngeal patency, or with undulation (J. E. Webb, I973). It is unlikely that burrowing was the primary driving force. First, urochordate (stage 2) larvae already have a notochord but do not burrow; in contrast, only appendicularians (larvaceans), cephalochordates and some vertebrates retain a complete notochord in adults. Whereas cephalochordates and some vertebrates burrow, the chord of the former is uniquely muscularized, supposedly as an independent burrowing specialization (Guthrie, 1975). The circular and longitudinal muscles of adult hemichordates differ from the segmented longitudinal muscles of chordates. Hemichordates lack a true notochord, segmented myotomic muscles, and a neural tube with segmentally repeating motor neurons. The two adult arrangements involve distinct burrowing styles and hence are mutually conflicting (Gutmann \& Bonik, I98I). These reasons invalidate the burrowing hypothesis.

Maintenance of pharyngeal patency is important, but the pharynx always occupies but part of the trunk. In contrast, the notochord always extends along the entire trunk and tail. Furthermore, the notochord differs from the pharyngeal skeleton in arising 
from mesoderm rather than the neural-crest precursors forming the pharyngeal skeleton. The absence of close association between pharynx and notochord invalidates a patency hypothesis.

Undulation requires not only a notochord, plus bilateral sets of longitudinal muscles, but also motor co-ordination generating synchronized alternating contraction (Gray, I953); it represents differentiation of a highly complex system. That this system developed simultaneously along the whole trunk is unlikely, and even less likely that it arose along the entire body (hypotheses 3 and 4 above). An 'initial' notochordal structure by itself is unlikely to have been able to support undulation.

However, it is plausible that a notochord could have stiffened a caudal appendage (or the posterior end of the trunk); such an appendage could be displaced by longitudinally arranged axial muscles connecting it to the trunk (hypothesis 2 above). Any such set of muscles could suddenly displace a floating organism-a much simpler task than sustained locomotion. Sudden deflexion movements, co-ordinated with the approach/ strike of a predator, would generate an unpredictable trajectory and with this reduce frequency of capture. These events could have occurred at the time of origin of new predators belonging to other phyla, such as arthropods, molluscs, and perhaps annelids (McAlester, 1968). Deflexion movements will have selective advantage if they are sudden and unpredictable; they do not require locomotion in a particular direction.

Any stiffening and increase in mass of the appendage, such as by diverticulating a rod of turgid cells, would allow exertion of increased force on the surrounding water; it would increase the potential escape acceleration. An early association of notochord and longitudinal muscle with escape is also in concordance with Coghill's ( I 9 I 4) observation that the initial motor behaviour of Ambystoma embryos facilitates avoidance, rather than locomotion. Certainly, the escape hypothesis explains the initially puzzling diversity of caudal and locomotory structures of urochordates; these may now be considered as remnants of an experimental radiation responding to the advent of large mobile predators (McAlester, 1968).

The acceptance of a caudal origin of the notochord does not explain the initial origin of a tail. It leaves open the possibility that a caudal appendage represents a by-product of ciliated locomotion, perhaps developed as a stabilizer, preventing the bilaterally symmetrical animal from spinning about its long axis (or directing its spin). It might have facilitated the development of horizontal movements as a distinct harvesting strategy, different from that of vertically feeding ciliated predators, such as ctenophores. (Feeding direction, in this context, is separate from the path of nocturnal migration, for instance, in larval Branchiostoma, J. E. Webb, 1969.) A post-anal tail is a derived state of chordates, unless the urochordate caudal appendage represents part of the trunk (cf. Jägersten, 1972). The escape hypothesis clearly suggests a function-associated stage in caudal stiffening. If the notochord arose in a tail, extension of the elastic notochord into the trunk is secondary. Caudal fixation to trunk could have returned the tail to the midline by elastic recovery (i.e. utilizing the energy expended during its deformation) rather than by cyclic activity of the muscles of the two sides.

\section{(6) The dorsal location of the propulsive complex}

That the nerve cord lies dorsally and is hollow are highly diagnostic synapomorphies of chordates. In contrast, annelids, arthropods and molluscs have solid internal 
concentrations of neural tissue that lie ventral to the alimentary canal (Bullock \& Horridge, 1965). This has apparently led to a number of hypotheses for the 'transposition' of the annelid-arthropod nervous system to the vertebrate state (cf. Gaskell, r 908); such hypotheses are quite unnecessary if the vertebrate nerve cord represents an infolding of the concentrated connective aspects of an epidermal nerve plexus. However, it remains of interest why condensation occurs dorsally rather than ventrally.

In chordates, the notochord, dorsal hollow nerve cord and myotomes form a functional complex and their development shows inductive interactions. Presumably the origin of an initially or secondarily paired muscle mass was associated with and probably followed that of the notochord; both preceded or occurred simultaneously with the concentration of nerve tissue. As the notochord induces the other tissues, its dorsal position rather than that of the muscular and neural systems must be explained.

An appendage used in a wagging movement could have any location. However, a caudal appendage used in laterally undulant propulsion best lies on the midsagittal plane, either dorsally or ventrally. It is difficult to posit a functional advantage for a ventral location, but there are several for the dorsal one. Dorsal placement of an undulant tail permits a bottom-swimming animal to generate a range of caudal pitching moments both depressing and lifting the head off the substrate. In a bottom-dwelling animal, a dorsal location of the appendage would be advantageous for escape movements, as the tail could swing more widely without impacting on to substrate irregularities or disturbing silty bottoms. For a free-swimming animal, the dorsal location would facilitate vertical orientation in the water column if the visceral organs were maintained denser than the axial system.

The development of a dorsal location for the notochord may have involved developmental factors rather than strictly functional ones. Whereas an appendage may be stiffened either by incorporation of a block of new tissue within a pre-existing mass (with existing functions) or by diverticulation of a fluid-filled space, the latter approach is more common and presumably easier developmentally. Also it retains the epithelial organization of the wall of the chamber (basement membrane and its collagen fibers); this generates a tension-resistant tubular hydrostatic skeletal element. Branchiostoma forms a muscular notochord by a rear-to-front infolding of the dorsal roof of the archenteron (I.ehman, I977), whereas vertebrates generally form the chord by delamination from the dorsal roof. 'The chord demonstrates a basically epithelioid pattern that suggests its origin as a diverticulum with a hollow core (cf. Damas, I944; Brun \& Garson, 1984). Furthermore, the cells of the archenteric floor tend to have high yolk content; hence, it is more likely that a stiffening diverticulum would form on the archenteric roof than its floor.

The location of the notochord determines site and development of the mesodermal tissues forming the muscular mass and associated neurectodermal elements. In cephalochordates the dorsal location of the axial muscles requires a dorsal neural tube. These animals lack centrifugal branches of the motor neurons and their myoneural contact is effected by muscular processes reaching inward to synapse on the surface of the spinal cord (Flood, 1966). Apparently, the spinal cord (with its basal (motor) portion most developed) was initially embedded within the axial muscles. 


\section{(7) The development of undulation}

Utilization of a caudal appendage as a deflexion device represents a protoadaptation for directed muscular propulsion. Powering of the wagging pattern by paired caudal muscles would represent a first step toward propulsion by lateral undulation; however, as noted above, the transition involved many ancillary aspects. Two major aspects require explanation. The first is the change from a temporally and spatially irregular predator strike deflexion to stereotyped and directed locomotion. The second is the shift from movements strictly by the tail to those involving the entire trunk beyond the head. Subsequent shifts led to sustained, and perhaps more rapid, locomotion.

Indeed, such directed and sustained mobility of the adult animal incurs several advantages. Unlike sessile animals, motile ones need not compete for limited firm substrates that will not silt over; they may avoid motile predators and predate actively; they may develop complex mating systems, and migrate to escape undesirable changes in the local environment. Increased mobility costs energy expenditure and increases need for food acquisition, in turn increasing exposure to predators. Mate location and need to synchronize reproductive events involve other costs. Cephalochordates, combine a capacity for short-term rapid motility with restriction to relatively small zones of densely occupied suitable biotope.

Change from an occasional wagging to a repeated sculling motion could have replaced ciliary propulsion. Motor co-ordination for regular oscillations would have required a pattern-generator. As the stiffened notochordal tissue is flexible and elastic, rather than rigid, its oscillation could develop continuous thrust, rather than the pushing phenomenon likely at very low Reynolds numbers. Thus, the energy imparted to the water is increased (as is the reaction force propelling the animal).

Thrust enhancement by the notochord, in turn, permitted continuing selection for features that enhanced its role in propulsion. Elongation would facilitate further curvature, leading to travelling waves that would smooth out thrust, generating an undulant rather than a drag-based oscillating pattern. Some level of stereotypy was likely; thus the undulating patterns of vertebrates generally pass front to rear, with the exceptions representing derived states. Elongation presumably provided a further advantage to elastic coupling of trunk and tail. Perhaps the change was initially ontogenetic (for reasons of size, see below). Any extension of the propulsive complex further on to the trunk must have involved major changes both in motor organization and in embryonic development.

Simply undulant and propulsively effective oscillation of a caudal portion by single, bilaterally arranged muscles, only requires a flexible appendage. However, undulant deformation of an intrinsically rigid trunk requires a more complex, presumably segmentally activated, muscular system. The flexibility of the pharyngeal and coelomic space would need to be increased by modification of the coelomic arrangement. Any such integration of the notochord and presumably segmented muscles into and around the suspension-feeding, digestive and reproductive aspects must compensate for the undulatory swimming movements, which tend to deform the pharynx and temporarily modify the ciliary feeding currents. Stabilization of the head in sustained swimming requires body-tail integration (Blight, 1977).

In phylogeny, the extension of the notochord into the trunk most likely proceeded 
along the mid-dorsal line anteriorly from the caudal region. Indeed, the caudal-torostral invagination of anamniote chordamesoderm (not seen in amniotes) may reflect recapitulation (Balinsky, 1981 ; Brun \& Garson, 1984), as it is concordant with the phylogenetic involvement of ever-increasing amounts of the trunk in locomotion. In vertebrate embryos, the progressive anterior displacement may have been facilitated by the role of chordamesoderm as a 'primary inducer' (Spemann, 1936, 1938) for the nervous system and differentiation of the somites, the sclerotome of which effects axial segmentation.

Segmentation of the paraxial mesoderm into somites is a process that begins after the presumptive notochord has completed its anterior progression. Segmentation of the caudal musculature of the ancestral species probably started at the caudal base. Later in phylogeny, further paired segments were presumably added distally. This pattern is still seen in the ontogeny of vertebrate tails (Ford, 1949) and indeed of the bodies of all elongate vertebrates. In phylogeny, the starting point (site of primary inducer) shifted gradually on to the trunk so that the forward end of the notochord came to lie more anteriorly; however, the fundamental ontogenetic process of front-to-rear mesodermal differentiation remained unchanged.

Muscular segmentation clearly follows segmentation of the embryonic connective tissues, myocommata in the adult; the myogenic tissues attach to their framework. The myosepta and their attachment both to the central axis and the integument, position the notochord within the trunk; they integrate the tensile forces imposed on the individual contractile elements (Bonik, Grasshoff \& Gutman, 1976). The staggering of the contractile muscle blocks in Branchiostoma mainly represents a variant reflecting the intrinsic asymmetry of this animal; as noted below, the feature is not yet understood.

The segmentation affects both muscular and nervous tissues. Early deuterostomes had an epidermal nerve plexus that incorporated widely distributed sensory, integrative and motor cells in a diffuse array deep to the surfaces that bear the propulsive cilia (Knight-Jones, 1952). Shift of some propulsive function from distributed cilia to concentrated dorsal musculature would have required a parallel shift, not only of the effector portion but of integrative aspects of the plexus. The integrative elements concentrated along the mid-dorsal zone, remaining connected to the sensory aspects represented by the rest of the original plexus. Invagination of the neural plate and its later rolling into a tube may represent the increased need for protecting an increasingly large, centralized nervous system. The several genera of enteropneust hemichordates may represent models of evolutionary experimentation in the concentration of nervous tissues. Such deuterostomes with mid-dorsal concentration and tubular invagination of nervous tissues retain continuity of the central nervous system with remnants of the plexus (Knight-Jones, 1952, 1953; Pickens, 1970). Many vertebrate derivatives of the neural crest and epidermal placodes show equivalent association with the spinal cord; they may have been homologous to the epidermal nerve plexus (Northcutt \& Gans, 1983). The central nerve tube must also have received direct input from anterior sensory cells that could scan the path of the moving animal.

This hypothesis suggests that the new features of the notochord, segmented muscles and nerve tube all developed from a mid-dorsal reorganization of embryonic tissues. Phyletically 'new' developmental mechanisms need not have been effected; rather the new tissues were modified as the dorsal lip of the blastopore grew inward along the 
dorsal lip of the archenteron and in the process induced a mid-dorsal strip of 'neurectoderm' while lateral presumptive mesoderm formed somites. In this interpretation, the phylogenetic development of chordates retains an addition of notochord-muscle-nerve to the embryo rather than a reorganization of the pre-existing features of developmental events (cf. Gerhart et al., I986).

\section{(8) Demands and advantages due to increased size}

The assumed incorporation of the notochord into the trunk probably involved changes in absolute size. Increased size increases the magnitude of temporary (absolute) deformation, requiring a mechanism for re-establishing shape. Some animals, such as coelenterates, can tolerate temporary deformation by conforming. Such animals show radial, rather than undulant movements. Unless the animal is stiffened, muscular contraction will deform its shape, rather than inducing directed, orientated and propulsive movements. Most important in the present context is that increase in linear dimensions of an aquatic animal increases the chances that it will encounter crosscurrents that will induce unacceptable internal tension, bending and shear. Whereas shear forces increase with absolute body size, they are unlikely to be substantial for animals operating at some depth in the open ocean. However, in shallow water and close to the surface or bottom, animals are exposed to waves and strong tidal currents, the influences of which in turn are size-dependent; 'narrow' and turbulent jets and currents are most likely to occur as fluids pass solid structures, such as rocks and reefs. The hydrostatic notochord facilitates deformation resistance.

A second set of size-associated features relates to active locomotion, as size determines the hydrodynamic regime within which the propulsion proceeds $(\mathrm{P} . \mathrm{W}$. Webb \& Weihs, 1986). Directed and sustained movement, rather than maintenance of position in the water column, establishes an advantage for elongation. The forces of profile drag, related to three-dimensional shape, are very large whenever the flow separates to form a wake; those for friction drag are proportional to area. Slenderization (possibly associated with encephalization, see below) and streamlining reduce the propulsive force that an animal requires to attain particular velocities in water. It greatly reduces profile drag, at the cost of a small increase in friction drag; hence the total drag is reduced (Bainbridge, 196r; Blake, 1983; P. W. Webb, 1975, 1978).

All of these aspects scale with size; profile and friction drag both increase with the square of linear dimension. The area of ciliary fields also rises as a function of the surface area; consequently, the absolute velocity of a cilia-driven body should be independent of size (assuming constant size and other properties of the individual cilia; the ciliary combs of ctenophores represent an effective modification). In short, the maximum velocity of ciliated animals of the same shape and ciliary pattern will be independent of size. In contrast, the mass of muscle, hence the muscular power, could rise as the volume of the organism (i.e. as the third power of the linear dimension, although the need for attachment surfaces reduces the actual exponent). Muscular arrays differ further from ciliary ones in their capacity to exert forces at sites distant from those of muscle placement, and for combining the effect of multiple units; this increases the magnitude of the force that may be applied at particular sites. Omitting differences of body shape, the shift to muscular propulsion will permit the organisms to enter a different velocity realm (i.e. one in which velocity scales with size and $\mathrm{I}<$ 
$R e<200 ;$ P. W. Webb \& Weihs, I986). Therefore, notochord and muscles have the advantage that they permit the larvae to become larger, transcending sizes and velocities for which ciliary transport might be an acceptable mode of propulsion.

Increased velocity allows animals to overcome currents unlikely for ciliated animals. Muscular locomotion also allows more effective dispersal. It would provide animals with the facility of leaving and returning to sheltered spots with less risk of being swept away by currents. It generates the potential for a greater decision-distance within which animals may escape the water current toward propitious resting or feeding sites; it also increases the decision-distance for sexually mature animals during mating. A more effective locomotor system would also have an obvious role in predator escape and predation.

Feeding may be no problem to a drifting animal, as the collision rate will remain constant as long as the suspension-feeding 'predator' and 'prey' drift randomly; the demands on a successful suspension-feeder gradually become more involved if the predators have to detect patches of food particles or as soon as the prey develop evasive responses. Active muscular locomotion would deal with these problems. Even the slightly increased velocity induced by sculling rather than cilia-driven movements facilitated an advantageous escape-response. Later, it provided a protoadaptation that permitted the prevertebrates to develop selective predation.

\section{IV. 'THE ORIGIN OF VERTEBRATES}

\section{( I) Protochordates}

It is now possible to review the adaptive patterns displayed by the protochordate radiation. Protochordates retain the conservative aspects or symplesiomorphies of larval suspension-feeding by means of mucus-entrapment. The group experimented, shifting the feeding mechanism inward, perhaps starting from arrangements equivalent to those in pogonophorans (Ivanov, 1963 ) and hemichordates to one equivalent to that in urochordates and cephalochordates (Barrington, 1965; Gilmour, 1979, 1982; Strathmann, 1982). At the time of the first metamorphosis, they developed an undulationgenerating complex of notochord, paired muscles, and nerve cord that superseded ciliadriven propulsion. Further experimentation occurs in adult locomotor modes; thus adult animals may burrow, be sessile, drift pelagically or swim freely.

The adaptive significance of some characters of the protochordates remains enigmatic. Two that pose difficulty are asymmetric larval development in cephalochordates and the original role of the protochordate atrium. Cephalochordate larvae exhibit pronounced lateral asymmetry during their development (Willey, I 894; Bone, I $958 a$ ). The mouth forms on the left lateral surface; however, a row of pharyngeal slits first forms on the left surface of the body and then migrates to the right side, after which the definitive left slits form and the axial musculature becomes staggered. Asymmetry has been associated with burrowing (but this begins about 70 days later) or more likely with feeding (Garstang, 1929; Barrington, 1965). Jefferies ( 1987 ) argues that asymmetry retains a calcichordate condition. The atrial chamber surrounds the pharyngeal apparatus, collecting the water from the pharyngeal slits to pass out via a single atriopore. An atrium is characteristic of many adult urochordates and cephalochordates, but its homology is uncertain (Godeaux, 1974; Young, I981). In cephalochordates it is 

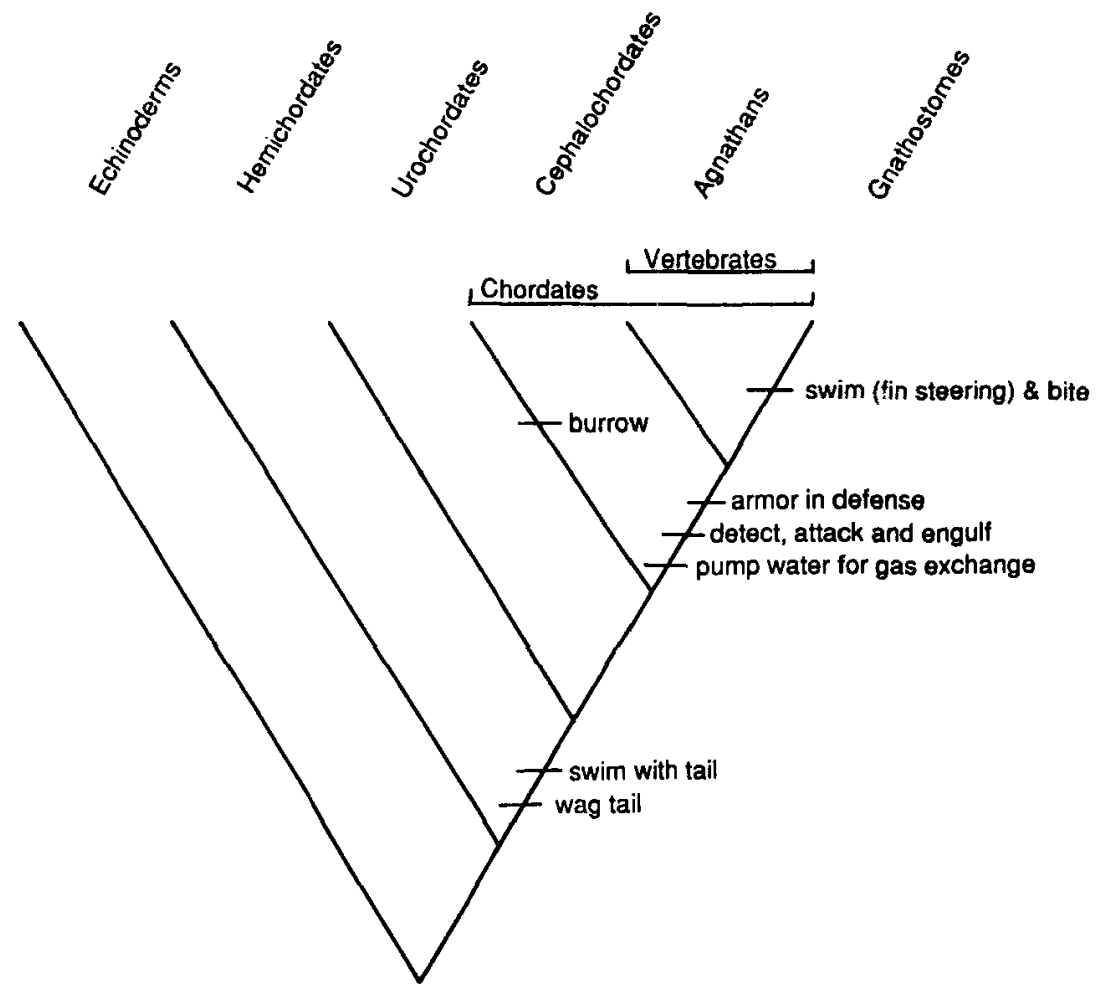

Fig. 2. Cladogram of the major groups discussed showing the fundamental changes in role.

formed at metamorphosis by outgrowth and fusion of ectodermal folds (so that it is lined by ectoderm provided with an epidermal nerve plexus) and is believed to protect the pharynx during burrowing (Stark, 1978); however, no urochordate burrows. Perhaps an atrium permits a cilia-powered animal to generate a coordinated and relatively rapid excurrent stream of filtered water away from the mouth; or it may be associated with reverse flushing (coughing, cleaning) mechanisms or other roles less directly associated with feeding.

Vertebrates differ from protochordates in having many morphological characters, related primarily to respiration, feeding and neural complexity, that develop or are induced by the neural crest and epidermal neurogenic placodes (Hørstadius, 1950; Gans \& Northcutt, I983; Northcutt \& Gans, I $98_{3}$; Table 1 ). The relative importance and sequence of origin of these characters represent basic problems in the understanding of the process of vertebrate evolution. Their resolution requires consideration of several sets of environmental demands, and of the ecological conditions and intermediate steps that presumably engendered the protochordate-vertebrate transition.

(2) Size, metabolism and the 'active' life

Adult cephalochordates utilize undulant muscular propulsion (that acts on the notochordal skeleton), as do most larval and some adult urochordates. For instance, the rapid undulant muscular propulsion in Branchiostoma permits them to move within 
sand beds or even to move among them (J. E. Webb \& Hill, i958; J. E. Webb, ig69, 1973, 1975). This makes it likely that muscular (rather than ciliary) propulsion occurred in adult prevertebrates.

Muscular propulsion allowing occasional undulant locomotion and burrowing increases the range and velocity of travel (in a directed rather than current-determined fashion), but locomotion remains size-limited (see above). Limitations of size are related to questions of gas exchange and distribution forced by the changing surface-volume relations of the organism (Schmidt-Nielsen, 1984); increased size presupposes solution of these problems by change of shape and mechanism.

Larger tissue volumes require the acquisition of more nutrients and gases; with increased size, diffusion becomes less adequate for internal distribution. Suspension feeding and gas exchange are surface-dependent and scale as the square of the linear dimension, whereas the metabolic rate of an organism is reflected in its tissue volume and might scale as a fraction of the cube of length (the reduction apparently reflecting the limitation imposed by numerous membrane-linked processes within the organism). Indeed, surface drag increases as the square of the velocity and relatively more propulsive energy is required for faster (muscle-powered) animals than for slower ones. Furthermore, the mass of tissue involved and hence its structural and maintenance requirements rise as some function near the third power. An animal may circumvent the problem imposed by the surface-volume relation upon its gas and nutrient requirements by changing the operant exchange principles, or may ameliorate it, either by changing the shape of the exchanger or modifying the exchange demand. (Species that operate at higher temperatures encounter such limitation at a smaller absolute size.)

The size-associated demand is more critical for gas exchange than food acquisition, as storage of gases is more limited; also protochordates lack the vertebrate mechanisms for temporary shifts to anaerobically supported burst activity (Ruben \& Bennett, 1980). Consequently, increased body volume requires exponential increase of gas exchange effectiveness or of its area. Further increase is demanded but increases metabolic scope, which permits additional muscular activity.

The low metabolic rate of Branchiostoma suggests that presumably more active prevertebrates had a higher one than the earlier chordates. Increased metabolic rate would have influenced other systems affected by surface relationships, such as food processing, internal distribution of gases and nutrients, and waste disposal. For instance, protochordate digestion is intracellular and digestive capacity should correlate with area occupied by gut cells. In contrast, vertebrate digestion is extracellular so that it can increase with the third, rather than the second power of length. (Absorption remains surface-dependent; note the complex foldings, digitization and sculpturing of the vertebrate gut.) Also, protochordates have a relatively smaller visceral mass than do vertebrates. Size differences become more obvious in considering the differences in the relative volumes of pharynx and coelom in protochordates and vertebrates. The excretory system reflects similar volumetric differences.

\section{(3) Problems in gas exchange}

The problems of gas exchange led to the first set of limiting conditions for an increase in adult size and swimming velocity. The pharyngeal apparatus of protochordates 
differs functionally and structurally from that of vertebrates. It serves only for feeding, whereas that of most anamniotic vertebrates has the major role in gas exchange (Northcutt \& Gans, 1983). The perforated pharynx of all protochordates is supported by a skeleton of coated collagen (Løvtrup, 1977); that of vertebrates is supplemented by compression-resistant cartilage (Rähr, 1981). In adult protochordates, the ciliapowered pump imposes a limit to the size of the pharyngeal slits, which are therefore narrower and more numerous than they are in vertebrates; the ranges of slit numbers do not overlap. The cartilaginous pharyngeal bars of vertebrates are much thicker and support transverse septa with projecting primary and secondary lamellae (or 'filaments' and 'lamellae' respectively; Hughes, I963; Mallatt, I984a). Protochordates transport water by ciliary beat, whereas vertebrates do so by contraction of the striated branchiomeric musculature. In cephalochordates, blood mainly flows through spaces within the tensile skeleton of the pharyngeal bars (Rähr, I98I); in vertebrates the branchial vessels are divided into capillaries that lie below a thinned and convoluted epithelium. The pharyngeal vessels of protochordates lack an endothelium (Welsch, 1975); the aortic arches of vertebrates are endothelium-lined (derived from the mesoderm of other regions; Noden, 1987, 1988) and enveloped by an extensive layer of smooth muscle (derived from neural crest; Le Douarin, 1982).

Five potential options for increasing gas exchange appear at the protochordatevertebrate transition. These are (1) shift of the site of gas exchange among the surfaces of the body, (2) increase of the area of the exchange surface, (3) reduction of its resistance to diffusion, (4) modification of the gradient by internal or external pumps, and (5) modification of the $\mathrm{O}_{2}$ or $\mathrm{CO}_{2}$ gradient by developing gas-transport molecules and buffering systems (Hughes, 1963; Gans, 1970; Liem, 1985).

Protochordates exchange gases over their entire body surface and pharyngeal structures are used primarily in suspension-feeding. Indeed, the metabolic demand of the ciliated surfaces of the protochordate pharynx could well generate an oxygen deficit in the blood of the dorsal aorta (see Barrington, 1965; Carter, 1971). These arrangements apply in all the deuterostome outgroups, making it likely that the protochordate arrangement was ancestral. Consequently, option I involves concentration of gas exchange into the pharynx, i.e. formation of gills is a derived condition characterizing vertebrates and representing the addition of a new respiratory site.

The pharyngeal region of all fishes has expanded complexly to an area orders of magnitude greater than that of the integument; this utilizes option 2 (Hughes, I984; Laurent, 1984). Subdivision of blood streams into capillaries immediately below the thinned pharyngeal epithelium and endothelium utilizes option 3 . The structure and arrangement of the pharyngeal vessels of protochordates and the branchial aortae of vertebrates (see above) utilize option 4 . Both cephalochordates and fishes show a directed internal circulation that traverses the bars in a ventro-dorsal direction, and is powered by ventral contractile elements (those of cephalochordates and hagfish represent contractile bulbs; urochordates and other vertebrates show a single heart). However, vertebrates, with the exception of hagfishes, innervate their cardiac pumps with neural-crest-derived cells. Also, vertebrates have added elastic-energy storage systems both internally (elastic conus for blood) and externally (elastic pharynx for water), thus utilizing option 4 . Vertebrates have also increased the internal gas-carrying capacity by development of cell-associated haemoglobin and buffering mechanisms, 
thus utilizing option 5. The utilization of all potentially possible mechanisms leading to an optimization of gas exchange reflects the potential importance of the system.

\section{(4) The development of gills}

The many aspects of the gas-exchange system are unlikely to have arisen simultaneously. Understanding of the phylogenetic origin and development of gills requires consideration of the flow dynamics of the two pharyngeal patterns, and the nature of the pharyngeal skeleton in prevertebrates. The pharynx of adult protochordates may be conceived as a perforated basket maintained patent by linear collagenous rods each covered by a stiffening, PAS-positive coating. The rods are inclined versus the long axis of the animal and would seem to incur minimal deformation; indeed, change in their angle would affect the width of pharyngeal slits. The number and length, but not the slit width, of the cilia-lined apertures increase as the animal grows. The beat of their lining cilia drives water from the pharynx. The effective number (and aggregate length) of slits doubles at metamorphosis; thereafter, it increases as the length of the animal increases, suggesting that it relates (inversely) to the maximum allowable width of slits and (directly) to body mass (Barrington, 1965).

In Branchiostoma, water flows from pharynx to atrium to outside. Hence, the pharyngeal pressure is above that of the atrium, and it in turn above external pressure. The exit diameter of the atriopore is controllable by a ring of muscle; this diameter, combined with the beat pattern of the wheel organ and pharyngeal cilia, must regulate the flow of water. The width of the slits (but not their height) is maintained by connecting cells and is probably limited by the ciliary length, as effective particle separation requires maintenance of a minimum velocity.

In contrast, the pharynx of lampreys and sharks consists of a small number of elastic cartilaginous bars and an array of branchiomeric muscles, the action of which can reduce the pharyngeal volume. Bulk flow rate and water velocity may be adjusted by matching pumping rate to slit diameter. Pharyngeal re-expansion is due either to the energy stored in pharyngeal deformation or (phylogenetically later) by muscular action (cf. Mallatt, I98I, for a review). In ammocoetes, the gill skeleton is unjointed rather than formed of articulated links, and the muscular pump and its central motor control is single-cycle (Rovainen \& Schiever, 1975; Russell, 1983a,b). Flaps of tissue form check valves so that water flows unidirectionally into the mouth and out of the gill slits (Mallatt, I98I). Water flows counter-current over the primary and secondary lamellae of the gills and leaves the pharynx directly to the outside; there is no atrium. (The gross architecture of the Pacific hagfish Eptatretus differs as the gills lie in pouches; however, on the fine structural level the cells resemble those of lampreys, elasmobranchs and teleosts, Mallatt and Paulsen, r 986.)

Whereas the pharynx of adult protochordates differs profoundly from that of anamniotic vertebrates, the pharyngeal organization of larval cephalochordates is slightly more fishlike. Larval cephalochordates lack an atrium and their pharyngeal pouches open to the exterior via the ectoderm (Willey, $189 \mathrm{I}$; van Wijhe, 1914; Olsson, 1983). Although adult cephalochordates have many more branchial slits (pouches), the number of slits $(8-10)$ in larval cephalochordates is only slightly greater than that of Recent vertebrates. The mouth being lateral, rather than anterior, movement of such an animal should generate velocity pressure, increasing the amount of water flowing 
through the pharyngeal region (a simple variant of ram ventilation). This occurs even in passive feeding during vertical drift, but would be enhanced during muscular propulsion. Any increase in the water flow should enhance filtration of food and probably pharyngeal gas exchange.

Any hypothesis about the transition to true gills must, then, account for at least six morphological phenomena. These are (1) the absence of an adult atrium, (2) the change in the skeletal material composing the bars, (3) the reduction and/or modification of pharyngeal arch number and architecture, (4) the formation of muscularized aortic arches and associated branchial vessels, (5) the change from ciliated to muscular pumping of water and (6) the development of a single muscular heart. Whereas there are no fossil data relevant to these phenomena, developmental and functional analyses permit tentative hypotheses, based in part on clues furnished by structural features of the larval Amphioxides, as well as by observations on the pharyngeal coughing (reverse water-flow) of Branchiostoma.

Amphioxides are interpreted as relatively large (7-14 mm; Franz, 1927), freeswimming (possibly neotenous) pelagic larvae that have prolonged their premetamorphic stages until they are at least three times normal length, and their gonads may mature prior to atrial closure (Bigelow \& Shroeder, I948; Bone, I $960 b$; Barrington, I965). These relatively large, muscle-propelled animals occur in the open oceans, indeed down to $2000 \mathrm{~m}$ (cf. Beebe, 1934; Bigelow \& Schroeder, 1948). No atrium (or restricting atriopore) has formed and the number of pharyngeal slits is proportional to size. Although their mouth is asymmetrical, it extends around the anterior end.

If prevertebrates had a large, active larval form similar to Amphioxides, increased respiratory exchange might have been adaptive for them. Swimming enhances the absolute amount of gas exchanged in the pharynx. However, activity also increases metabolic rate and hence the need for gas exchange, reducing any net benefit. Intermittent muscular compression of the prevertebrate pharynx might have uncoupled these effects. This would make capillarization of the branchial circulation and thinning of the overlying epithelium advantageous. Filtration (and gas exchange) might be disturbed by pressure changes in the pharyngeal basket effected by muscular undulations of the trunk. However, restriction to the postpharyngeal region and alternation of propulsive and compressive movements might reduce the effect so that ram ventilation could increase the exchange. If an atrium occurred in ancestral chordate species, it would have closed at a larger size; indeed no atrium need form.

How could such a transition from suspension-feeding to gas exchange have occurred? In amphioxus, the cilia of the pharyngeal bars apparently power much of the flow of water through the linearly arranged pharyngeal basket (Barrington, 1965). Their action would be enhanced (but not substituted for) by ram ventilation. Intermittent muscular contractions of the pharynx could further increase movement of water, but unidirectional flow would require a check valve system. Intermittent increase of water flow would increase the pharyngeal gas-exchange relative to the external integument, but also the demand of pharyngeal muscles.

Compression of the atrium by adult cephalochordates produces backflow of water, flushing the pharynx in response to any stimulus (Parker, 1908). However, compression only occurs after atrial closure at metamorphosis. Direct deformation of the stiffened pharynx would narrow the pharyngeal slits. Muscular action requires a modification 
that would allow the pharyngeal frame to deform and return to its previous shape (and volume). In ammocoetes, this effect is attained by cartilaginous reinforcement of the collagenous pharyngeal bars (Roberts, I950).

The proposed deformability of the pharynx leaves open the question of what powered the deformation. Two motor patterns are possible. The first is that the premetamorphic pharynx was irregularly acted on by synchronous, rather than staggered, contraction of the axial muscles, which in larval Branchiostoma invest the dorsal half of the pharynx. A model for a different pump is provided by the transverse and striated subpterygial muscles of adult Branchiostoma (Gans \& Northcutt, 1985). Their 'coughing' action apparently allows flow-reversal and pharyngeal-flushing out of the 'mouth' (Bone, I 961). The subpterygial muscles are innervated by motor neurons that leave the cord dorsally and follow the muscle into the atrial folds as these close at metamorphosis (Bone, I $960 \mathrm{a}$ ). Paedomorphic arrest of atrial formation could have led to migration into the primary pharyngeal bars; this would suggest homology with the present branchiomeric muscles. Muscular contraction, coincident with velar closure, would force the water through the pharyngeal slits, whereas velar opening would allow refilling of the pharynx.

The origin of the elastic component is suggested by the chemical similarity of the PAS-positive proteoglycans (chondromucoids) of vertebrate cartilages to the similar ones forming the cupulae of neuromasts, such as occur in lateral line organs (Iwai, I 967); this indicates a possible homology of the cells initially secreting them (Northcutt \& Gans, 1983). Both vertebrate cell-types generate extracellular matrix, respectively in neural crest (branchial cartilages) and neurogenic epidermal placodes (neuromasts). Mechanoreceptive neuromasts are ubiquitous in the acousticolateralis systems of anamniotic vertebrates in which the cupulary proteoglycans serve as sensitivity (transduction) enhancers. Protochordates show extensive pharyngeal and atrial nervous systems, but generally lack cupular structures in their external mechanoreceptors (Schulte \& Rieh1, I977; Bone \& Best, 1978; Baatrup, 198I); exceptions occur unilaterally in some adult tunicates (Bone \& Ryan, 1978). Although the branchial bars of cephalochordates appear to lack cupulary structures, sensory cells lie immediately adjacent to them; these are presumably associated with the epidermal nerve plexus (Holmes, 1953; Bone, 1958b). Possibly such prevertebrate cells initially monitored mechanical deformation of the pharynx. Secretion of elastically compliant proteoglycans would have protoadapted them for aiding elastic recoil. Development of the elastically compliant material may have been accelerated near metamorphosis. As the elastically compliant cartilages could be sculptured, projecting primary and secondary lamellae could support the amplified gill surfaces of the relatively large, sexually mature animals.

Larger respiratory surfaces, capable of increasing the absolute amount of gas absorbed, established an advantage for further change to directed and powered internal perfusion with blood. Distributed contractile bulbs become modified into a central heart at the base of the single ventral aorta, as an advantageous corollary to active locomotion and increased size. Every higher invertebrate longer than a centimetre shows directed circulation of fluids containing gases and nutrients. 'The protovertebrate centralization of the cardiac system probably developed in parallel with origin of the neural crest; vertebrate contractile bulbs are innervated by crest-derived cells, and the 
heart of petromyzontids and gnathostomes (but not myxinoids) is supplied by crestderived second-order motor cells of the autonomic system (Starck, 1978). The processes of pumping of blood and capillarization would be mutually reinforcing, with capillarization and distribution of endothelium being epigenetic.

These processes lead to lamellar structures on the gills and later to the countercurrent gas exchangers ubiquitious in gilled vertebrates. Specialized exchangers remove the respiratory limitation to locomotion.

It seems useful here to mention arguments suggesting that gills have arisen twice (see Jarvik, I980, for literature). First, the embryonic origin of the epithelium covering the gills is claimed to be ectodermal in agnathans and endodermal in gnathostomes (Jarvik, I980). However, Mallatt (1984b) indicates that the embryological evidence is incomplete; also vascularized surfaces are clearly subject to epigenetic influences. Secondly, the skeletal elements supporting the branchial bars of agnathans lie external to the exchange surface, whereas those of gnathostomes lie internal to it. However, Mallatt $(1984 b)$ noted that Recent agnathans and gnathostomes both have external and internal skeletal elements. In agnathans, the gills are moved mainly by the external element of the skeletal supports; in contrast, in gnathostomes the internal element moves the gill.

This architectural difference appears to reflect a functional characteristic. In agnathans the muscles act directly on the outside of the skeleton, and the system recovers by elastic recoil (Rovainen $\&$ Schieber, 1975; Russell, I $983 a, b$ ); an internal skeleton would be less likely to unfold the gills. (The risk that the internally placed gills would be damaged during the ingestion of prey seems to be unimportant for the feeding pattern of Recent species.) However, the gnathostome arch skeleton is composed of articulated links; no elastic recoil is involved, rather the pump is driven by two sets of muscles, the power stroke being coincident with the expansion phase (Lauder, $198_{3}$, 1985). This evolutionary change permits the development of an internal skeleton with special protective devices, such as gill rakers.

\section{(5) The cell lines of the neural crest}

The development of cartilage is a good example of a problem that will appear repeatedly, namely the origin and subsequent phylogeny of the diverse neural, muscular, secretory and supportive cell types developing from neural crest and ectodermal neurogenic placodes. The homology of the epidermal nerve plexus of nonchordate deuterostomes and the derivatives of the neural crest and placodes (Northcutt \& Gans, 1983) reflects both the structural (and functional) similarity of the plexus to these derivatives and the absence of most vertebrate types of supportive tissues in other deuterostomes.

An epidermal nerve plexus includes sensory, integrative and effector cells. The presumably homologous neural and muscular tissues share the cellular properties of sensitivity and contractility, whereas the supportive derivatives lack these properties but may secrete proteoglycans and perhaps hydroxyapatite. As the uniquely vertebrate supportive tissues, such as the cartilage of the branchial system, form ontogenetically from the neural crest, they are homologous to the epidermal nerve plexus (Northcutt $\&$ Gans, 1983). Neural-crest tissue of the preotic region of vertebrates produces all types of the connective tissues which are produced more posteriorly by mesoderm. This 
suggests that these diverse cell types either derive from a single cell line that once produced only nervous components or that the epidermal nerve plexus of the ancestral animals also contained supportive elements, such as glial and sustentacular cells (Baatrup, I $98 \mathrm{I}$ ), that later in phylogeny generated the supportive tissues of the head? Unfortunately, this conflict cannot now be resolved.

The argument that the chondrocytes that form the pharyngeal bars of vertebrates are phylogenetic derivatives of mechanoreceptors or of their supportive cells arises from consideration of the neural crest origin of these chondrocytes. Other hypotheses are possible, but each would involve arguments based upon other cell lineages of the neural crest. Similar problems are encountered in considering the origin of the smooth muscle sheathing the aortic arches, of dentine and of dermal bone.

'l he smooth muscle sheathing the aortic arches also derives from neural crest (Newth, 1956; Le Lièvre \& I.e Douarin, 1975). At least two hypotheses may explain its origin. Both sensory and motor neurons (indeed most cells) contain sizeable amounts of actin and myosin, thus smooth-muscle cells could well originate from either type of neuron. The free surfaces of sensory mechanoreceptors such as neuromasts are characterized by stereocilia packed with actin. These sensory cells also receive efferents, the cell bodies of which lie within the brain stem. If smooth-muscle cells originated from sensory neurons, these must have lost their sensory function and central connexion (e.g. afferent innervation). In contrast, smooth muscles may have arisen by transformation of peripheral motor neurons initially supplying the endothelium or some portion of the contractile bulbs. Similar hypotheses may account for the phylogenetic origin of aortic body receptors and chromaffin tissues.

There are some obvious corollaries. The first is that the sensory and effector neurons would be ciliated (Baatrup, I 98I) and the cells of descendant lines might be ciliated as well. 'Ihis explains why the several kinds of special sensory neurons are ciliated; this is not surprising as these tissues are generally accepted to be ectodermal in origin. Furthermore, cilia appear in such 'mesodermal' tissues as cartilage (Goel, 1979); whereas this unusual occurrence may reflect centriolar malformation, it is congruent with the origin of cartilage from epidermal cells of the nerve plexus.

\section{(6) The origin of branchiomeric muscle}

Traditionally the branchiomeric muscle that surrounds and deforms the pharynx of vertebrates is assumed to derive from the hypomere (lateral plate mesoderm). However, Noden (1984, I987) notes that this view is supported by little descriptive and no experimental evidence. The primary support comes from the innervation of branchiomeric muscles by nerves that leave the brain stem dorsally in a manner comparable to that of the dorsal spinal nerves of lampreys that innervate the smooth muscle of the gut (Herrick, 1899).

This similarity has been emphasized even though branchiomeric muscles are striated and directly innervated by first-order motor neurons located within the brain stem. In contrast, visceral muscles are innervated by second-order motor neurons of the peripheral autonomic nervous system. The differences, if mentioned, have usually been dismissed on the spurious functional grounds that the striation of fibres reflected voluntary activation.

The conflict has recently been resolved experimentally. The branchiomeric muscles 
of vertebrates originate by ventral extension from anterior paraxial mesoderm (Noden, I $982,1983 a, b, \mathrm{I} 987$ ) located anterior to the zone that forms the somites proper; thus the preotic somitomeres do not form somites (Meier, 1979, 1981; Meier \& Packard, 1984; Jacobson \& Meier, 1984). Hence, the branchial muscles are akin to axial skeletal muscle explaining why they are striated and directly innervated by first-order motor neurons within the brain stem. However, the embryological data do not account for innervation by cranial nerves that leave the brain stem by a dorsal rather than a ventral route.

Whereas chordates are generally assumed to exhibit only a single pattern of myotomal innervation, there are actually two. That most obvious in the trunk of both Branchiostoma and vertebrates involves somatic motor neurons located within the basal plate of the spinal cord. Those of vertebrates exit ventrally to innervate the striated muscles originating from myotomes. Those of cephalochordates end on the surface of the spinal cord; there they synapse with centrally directed non-contractile processes of the muscle cells (Flood, 1966, 1968). A second pattern is seen in the anterior end of amphioxus. Somatic motor axons leave the neural tube via a dorsal cranial root that then proceeds ventrally to innervate the striated subpterygial muscle of the atrial floor (Bone, I960a). Late-developing subpterygial muscle arises at the time of metamorphosis from a ventral portion of the anterior 'head' myotomes (Bone, 1961). Inhibition or delay of atrial development leaves the primordium of the pterygial portion of the myotome close to the dorsal aspect of the pharyngeal slits. Downgrowth into the branchial arches, rather than the metapleural folds, would provide the substrate for vertebrate branchiomeric muscles. Hence, the subpterygial musculature of amphioxus appears homologous to the branchiomeric muscles of vertebrates and explains the curious (dorsal nerve) innervation of the latter. Smooth-muscle fibres, associated with the pharyngeal slits of larval Branchiostoma, disappear at the time the atrium closes (cf. Bone, $1959 b$; J. E. Webb, I 969). Their ultrastructural study seems desirable.

This hypothesis does not appear to account for the origin of separate dorsal and ventral cranial nerve innervation for two distinct series of striated muscles within the head. One hypothesis would consider all striated muscles part of an originally single series and another to have them derived separately. If the structural arrangements in cephalochordates and vertebrates are considered homologous, it is likely that the branchiomeric series (dorsally innervated muscles) and extrinsic eye-muscle series (ventrally innervated muscles) arose phylogenetically from different portions of head mesoderm. This hypothesis is supported by a recent claim that avian extrinsic eye muscles arise embryonically from prechordal rather than from the more posterior paraxial mesoderm which gives rise to the branchiomeric muscles (Wachtler et al., 1984).

Alternatively, both vertebrate muscle series arose from paraxial mesoderm innervated solely by a series of ventral nerves as in the case of the myotomal derivatives in the trunk. Such a hypothesis would require the redirection of axons of the neurons innervating the branchiomeric muscles from ventral into dorsal cranial nerves. Similar rerouting of visceral motor axons is believed to have occurred in the trunk of all gnathostomes (a shift of visceral motor axons from dorsal to ventral spinal roots; Ariëns Kappers, Huber \& Crosby, 1936). Assumption of a single origin for branchiomeric and extrinsic eye muscles requires additional phylogenetic steps of unknown significance. 
Perhaps the most important information conveyed by the new data on the embryology of branchiomeric muscles is that they did not arise in situ by muscularization of hypomeric tissues, but involve invasion of paraxial mesoderm to surround the pharynx laterally and ventrally.

The anterior portion of the vertebrate branchiomeric mass is formed in a zone anterior to the tip of the notochord. In Branchiostoma the notochord extends beyond the pharynx, whereas in vertebrates the muscle mass extends anterior to the otic zone to the optic region. The muscularization affects what has been termed a 'new head' (Gans \& Northcutt, 1983 ), a zone of outgrowth containing the anterior sensory capsules and the new anterior portion of the brain, including an expansion of the alar, but not the basal portion of the brain stem. Embryonically, some of these muscles form anterior to the influence of the notochordal tip (primary organizer) and are innervated by neurons that course anteriorly to reach them.

\section{(7) The shifts in the feeding pattern}

The earliest vertebrates are modelled as predators (Gans \& Northcutt, 1983; Northcutt $\&$ Gans, r 983 ) and this will be elaborated further in this section. The Middle to Late Cambrian period of probable vertebrate origin saw the advent of new predators in other phyla. A variety of arthropods, molluscs, and perhaps annelids, departed from suspension feeding and selectively attacked particulate food items. The appearance of formidable predators, among other factors, apparently led to the evolution of thickened exoskeletons and integumentary armour by many kinds of multicellular organisms (McAlester, 1968). In short, the advent of predators appears to have changed the nature of their prey.

Utilization of particulate and larger prey is of substantial benefit to a predator. Increasing the size-range of ingestible prey objects widens the niche of predators, either for brief intervals or extended periods. Other factors being constant, doubling of the linear size of ingestible particles potentially yields an eightfold increase of nutrient quantity (per particle) or an eightfold reduction in search time. This may lead to specialization on larger food or intermittent increase in the range of those ingested.

Presumably, the advent of successful radiations of freely floating suspension feeders (which perhaps were in turn harvested initially by relatively few kinds of freely floating, pelagic predators) must have had a substantial influence on the density and community structure of their prey. The biomass available for a randomly harvesting suspensionfeeding predator must have been reduced further with the development by the zooplanktonic prey of evasive responses such as those above noted in association with the origin of a notochord. Hence, the shift to selective particulate feeding in prevertebrates may be seen as responding to the scarcity of easily attained prey. Specialization must have shifted predators away from suspension feeding, utilizing particles of larger size, and hence greater energy content. However, each modification from random to directed predation must have affected and been reflected in the resource base.

Members of all groups of possible prevertebrates use cilia-transported mucous bands for feeding. However, these animals differ in the exact site at which the capture or filtration of suspended particles takes place. The zone in which the mucus is secreted and the structures involved in transporting it also differ. This variation suggests that 
suspension-feeding, in different groups of hemichordates and protochordates, is a function of convergent and non-homologous structures.

It has been suggested (Jollie, I982) that the earliest chordates were free-living predators. This is unlikely, for no known hemichordates or protochordates has paired (external) distance receptors (Bone, 1959a, 1960c). Also pre-metamorphic larvae of non-vertebrate deuterostomes feed by means of internal or external ciliated mucous strips. After metamorphosis, the feeding surface may be located externally on tentacles or spread across the integumentary surface, as in hemichordates and pogonophorans; in contrast, urochordates, cephalochordates and suspension-feeding vertebrates trap particles in the pharyngeal region. A few vertebrate embryos retain traces of an early ciliated stage (e.g. amphibian and lungfish embryos; Whiting \& Bone, I980), but this is unlikely to provide evidence for the condition in the earliest vertebrates.

Most suspension-feeders are non-selective in uptake of food. All particles of a particular size-range are acquired (Mallatt, 1985), although 'noxious' ones may be selectively rejected, presumably after being determined by tactile or chemical senses (Parker, I908). Suspension-feeders may shift from zones of low to high particle density (J. E. Webb, 1975); although protochordates do avoid noxious particles there is no evidence that suspension-feeding protochordates pursue individual ones. Cephalochordate larvae apparently drift downward and feed on objects then encountered (J. E. Webb, 1969). Occasional ingestion of single particles appears random, rather than involving active approach of particular ones. In order to acquire specific food objects an animal with muscularized propulsive system must develop orientation. It would be of interest to know whether the larger Amphioxides remain indiscriminate suspensionfeeders, are able to select particular particles or to identify and harvest patchy prey (phytoplankton blooms).

Fossil ostracoderms appear to have lacked structures indicating suspension feeding (Northcutt \& Gans, I 983). Indeed, many adults were flattened and some had a ventrally situated, recessed and posteriorly displaced buccal aperture. These attributes militate against suspension feeding and led to the hypothesis that ostracoderms fed on detritus. The suspension-feeding view can be rejected even more firmly in the light of the overwhelming evidence of their sensory systems.

The earliest vertebrate fossils had olfactory, optic, and acousticolateralis systems; in short, the major paired external sense organs, associated in Recent vertebrates with distance- and direction-reception, were already present. The cavities for these sense organs are large and complex; they housed multicellular structures, incorporating several classes of receptors and accessory components. Only predators show the origin of complex distance-receptors, making it likely that their appearance signals a shift to predation in adult vertebrates. Mallatt's hypothesis (1984a) that distance-receptors could have allowed suspension-feeding vertebrates to detect patches of suspended food lacks corollaries in suspension-feeding lineages of other metazoans. Neither amphioxus nor larval lampreys have distance receptors; lampreys only develop pattern vision at metamorphosis (Rubinson et al., 1977; Kennedy \& Rubinson, 1984).

What were the steps leading from suspension feeding to active predation? Initially, minor shifts in the animal's floating position could direct the mouth toward prey particles contacted by accident. Once prey touches the mucous strip, ingestion follows. For example, downward-drifting Branchiostoma larvae ingest prey as wide as the 
diameter of their laterally displaced mouth (J. E. Webb, 1969). Once near-field effects (Bone \& Marshall, 1982) allowed detection, for instance, of ciliated invertebrate larvae, they could easily be approached because of the differential velocities between ciliary and muscular propulsion. Integumentary mechanoreceptors or chemoreceptors could steer repositioning of the buccal cavity vis-à-vis contacted prey objects. This phase would involve enhancement of distance-receptors, as increased detection-distance is highly advantageous whatever the categories of food. The ability to move selectively into blooms of particles in coastal regions and perhaps estuaries may have followed.

Two reasons suggest the unlikelihood that most of the transition from passive to active predation occurred in the free-swimming mode. First, capture of prey swimming actively in three-dimensional space requires complex orientation; such prey differs from drifting objects. Secondarily, the mucous entrapment system might encounter ingestion problems for active prey. Both of these problems could be overcome by benthic animals feeding on semi-sessile soft-bodied invertebrate prey.

Branchiomeric muscles generate the potential for local constriction of the pharynx and the development of an oral engulfing mechanism. Propulsion by the segmented myomeric muscles could force the buccal aperture into contact and push it over the prey. Once the particle had partially entered, contraction of the anterior portion of the branchiomeric musculature (developed for ventilation) would drive the prey into the alimentary canal. Ingestion could have specialized further with modification allowing selective distension and contraction of the buccal aperture and the application of dermal elements to the prey. The structures of the mouth of myxinoids (Dawson, 1963) model ways that prey may be ingested and cut in the absence of articulated jaws. It is also tempting to refer to deep-sea ascidians, some of which are supposed to predate on nematodes and small crustaceans; however, their feeding behaviour has not been observed (Alexander, r 975 ).

Hence, the shift to feeding on larger particles is unlikely to have taken place far from the bottom. Swimming close to the bottom, post-metamorphic prevertebrates could have located semi-sessile food objects and pushed them against the substrate, thus forcing them into the buccal aperture. The earliest heterostracans (and many later ostracoderms) were heavy and often of flattened cross-section (Moy-Thomas \& Miles, 1971), a shape probably associated with intermittent bottom-moving rather than with regular free-swimming (i.e. they were benthic rather than pelagic; cf. Arnold \& Weihs, 1978). The later fusiform ostracoderms probably represented a later stage, perhaps with more rapid response times, improved sensory and motor co-ordination, and structural modifications, allowing free predation (rather than accidental contact-capture) in the water column.

Particulate feeding involved shifts in the proportions of the pharyngeal components and the need for protection of the gills. Again, larger food particles require a stomach or other enlargement of the alimentary canal. Rapid passage of the food makes for poor assimilation efficiency; with delay, digestion and absorption may advance further before defecation. Ciliary transport obviously is ineffective for the digestion and breakdown of larger particles. The development of a muscular (hypomeric) wall to the gut, and the change from intracellular to extracellular digestion, are significant advances. Muscularization of the intestinal wall also restricts movements of ingested prey and consequent damage to the gut. In vertebrates, the system is controlled by 
derivatives of the neural crest, which furnish many secretory cells, and the entire enteric nerve plexus (Gershon, 1987).

\section{(8) The development of sense organs}

Protochordates and vertebrates differ more profoundly in their sensory organs than in other systems. Cephalochordates possess chemoreceptors, mechanoreceptors and photoreceptors, the two former generally associated with the epidermis, the latter laying within the nerve tube (Baatrup, 1983; Bone \& Best, 1978). However, with rare exception, all are unicellular sense organs. In contrast, the major sensory systems of vertebrates are multicellular and also include electroreceptors as a new type. All compound vertebrate sense organs appear to develop in association with placodal tissues. All include substantial and complex sustentacular elements that produce various extracellular encapsulating tissues enhancing transduction (see above).

In both cephalochordates and vertebrates, all the special sensory receptors are intrinsically epithelial; apical microvilli (stereocilia) frequently surround a central cilium (kinocilium). The simplest hypothesis on the phylogeny of the earliest chordate chemoreceptors is that they were similar to those on the rostrum and surrounding the mouth of Branchiostoma, which apparently lack chemoreceptors within the pharynx (Baskin \& Detmers, 1976), although they have receptors similar to the taste-buds of vertebrates on their oral cirri (Schulte $\&$ Riehl, 1977; Bone $\&$ Best, 1978). Localization and thus increase in density of the rostral detectors presumably resulted in the olfactory organs of vertebrates. Their chemoreceptors are generally of three types. The "common chemical sense' does not involve a specialized receptor but is mediated via unmyelinated nerve terminals in the integument (Finger, 1983 ). Olfactory and gustatory reception is characterized respectively by two types of epithelial organs, and taste-buds by olfactory receptors, distinguished by their location, innervation and central projection. Vertebrate taste-buds develop from the pharyngeal region. Although some fishes show taste-buds on the surface of the skin, these form secondarily. Vertebrates react to the taste of food within the pharynx; they commonly reject prey after it has been partially or completely ingested (Atema, 1971).

The photoreceptors of cephalochordates are restricted to simple cellular elements distributed along the neural tube (Eakin \& Westfall, 1962), whereas those of vertebrates are complex, median and lateral. Vertebrate photoreceptors develop by evagination of the neural tube and clearly derive from ciliated cells. Even if accessory organs such as cornea, lens and iris are excluded, photoreceptors of protochordates and vertebrates appear very dissimilar.

The photoreceptors of prevertebrates are likely to have been involved in the entrainment of diurnal and circannual information and provided minimal means of orientation in the environment. Once the animals recognized sudden changes of the light-intensity they might detect the approach of predators, as do other living deuterostomes (Parker, 1908). With increase in body size, increase in the area of the CNS devoted to such tasks presumably led to evaginations from the new anterior portion of the nerve-tube (which also brought the senses closer to the surface of the larger animals). The process is modelled by early stages of vertebrate eye formation.

It is possible but unlikely that pattern-vision initially allowed the location of denser regions of suspended particles; most retinal ganglion classes of anamniotic vertebrates 
code for novelty and movement rather than for complex environmental features (Ewert, 1980). Hence, pattern-vision was probably initially associated with predation on moving objects. The initial involvement of sustentacular cells is unclear. Conceivably, the ectodermal accessory components of the eye originated separately from the sensory cells. They may have served non-visual functions and only secondarily become associated with the developing retina. Alternatively, placodal development might have been induced by the shift of sensory cells to the surface; evolution of cornea and lens thus may reflect the path of refinement of pattern vision. However, such a combination of sensory and non-sensory structures has no parallel in any other sensory system of deuterostomes.

Vertebrates possess a range of complex mechanoreceptors, including receptors of the inner ear (otic organ), neuromasts of the lateral-line system, and electroreceptors (ampullary organs). The common functional unit is a ciliated epithelial cell (hair cell) similar to the simple, ciliated mechanoreceptors of amphioxus. This leads to the postulate that the skin of the earliest chordates contained a ciliated epidermis used for propulsion, as well as scattered, mechanoreceptive ciliated cells (associated with the epidermal nerve plexus), as in living cephalochordates (Bone \& Best, r 978; however, these have a reduced epidermal nerve plexus).

With the phylogenetic origin of an adult with muscular propulsion, the initial ciliated epidermis lost its local effectors (i.e. cilia). Hence, the unity of the epidermal nerve plexus suffered a functional displacement of its propulsive and sensory components. Processes of the striated muscle fibres formed direct motor synapses on to the basal portion of the nerve-tube, so that the interneurons were concentrated in the spinal cord. Directional locomotion carried with it advantages for shift of the sensory cells to an anteriorly facing position and their input to the anterior end of the nerve-tube.

These sensory cells of the anterior body region increased in importance and aggregated into compound mechanoreceptive organs, as generally occurs in areas of significant information input (cf. Schulte \& Riehl, 1977; Vinninkov, 1982). Their multicellularity may be modelled on the neuromast organs of most anamniotes and some tunicates; these contain both sensory and supportive cells, the lattcr almost certainly secreting the proteoglycan coating (cupula) for the sensitive hair cells (Bone \& Ryan, 1978). Also, the anterior concentration of sensory cells led to specialization; subgroups of mechanosensory cells became more sensitive to the detection of light, pressure and other stimuli. The major sensory change for distance reception required both an increase in detector sensitivity and in positional information.

There might well have been selective pressure for arranging some of these organs into lines or patches, similar to the arrangements of the lateral line system. The detailed reasons why the lateral lines are arranged in so many different ways may remain unclear; however, bilaterally symmetrical animals concentrate mechanoreceptors in anterior bilateral arrays about the vivinity of the mouth. Still, it is impossible to reject the idea that the detailed patterns lack a current role, with multiple potential patterns sufficient for scanning the anterior environment.

One interpretation of the phylogenetic derivation of the inner ear is that it represents an infolding of a portion of the neuromast system. However, the difference in central connexions of the inner ear and lateral line in Recent anamniotes, provides no reason for one preceding the other. Nevertheless, similarities in the systems support the hypothesis that both evolved from mechanoreceptive organs. 
Chemoreception and mechanoreception may have monitored close distances, letting the animals decide whether to ingest accidentally contacted prey. However, neither these nor vision were likely to have been the initial senses to provide accurate information on distant objects. The development of visual pattern detection must have required many evolutionary steps; it was long before images were sufficiently detailed to permit discrimination at a distance. Interpretation and differentiation of distant signals would have been equivalently difficult for neuromast mechanoreceptors, particularly so in small animals in which the distance between the lateral sites was short. Olfaction (unless mediated by currents or winds) is notoriously non-directional, more likely leading to general arousal.

Consequently it is predicated that electroreception was the first distance sense. Unlike light, pressure and chemical signals, directional electrical cues represent unique signals that are almost always generated by living organisms. Hence, even a very simple pair of anterior electroreceptors would signal presence and direction of potential prey. Locomotion in the indicated direction should bring the predator into a range in which other sensors may facilitate further decisions about potential prey.

Presumably, one subpopulation of integumentary mechanoreceptors differentiated into electroreceptors. Mechanoreceptors of the ordinary lateral line are sensitive to strong d.c. fields (Bodznick \& Northcutt, 1980). The sensitivity of these mechanoreceptors could be increased by lowering the cell-membrane resistance or by increasing the resistance of the surrounding region. In either case, they become capable of detecting the electrical fields generated by other biological organisms. Further discussion of mechanoreceptors and electroreceptors in vertebrates involves consideration of the dermal armour, for there is ample evidence that these systems are interrelated (Orvig, I972; Schaeffer, I977; Northcutt \& Gans, I983).

\section{(9) Early stages of mineralization}

The earliest integumentary mineralization of (fossil) vertebrates apparently consisted of small units termed odontoids (odontodes) comprising superficial and deep components (Orvig, I 977; Reif, 1982). The superficial component comprised an outer enameloid and an inner dentine layer that penetrated through the epidermis; the deep component consisted of a subdentinal spongy and a deeper laminar or acellular bony layer. Study of fossil armour suggests that its superficial layers formed earlier embryologically than did the deep (Denison, I 967, 1973).

In fossils, the superficial component appears to have contained several classes of invaginations. Some of these, lined with superficial enameloid, had overall dimensions matching those of the electroreceptive ampullary organs of Recent fishes (Thompson, I 977). However, a recent study in Neoceratodus suggests that some of these passages were vascular (Northcutt \& Bemis, I 987). Other grooves and canals penetrate both the enameloid and the dentinous layers of the fossils; in location, pattern and dimensions these remind of those of the lateral-line system of living anamniotes; they have been interpreted as lateral-line vestiges (Stensiö, I927; Denison, 1947).

The dentinal component contains a series of radiating vertical channels similar to the tubules of modern dentine. It is assumed that the basement surface of the latter was covered by the cell bodies of odontoblasts, the apical processes of which filled these canals but did not reach the free surface. The dentine of modern teeth is highly sensitive, but it is not clear whether the odontoblasts themselves are sensory (or are 
innervated directly), or whether the high sensitivity of the tissue is due to the extensive ramification of free nerve endings within the deeper pulp cavity. We lack information on the embryology of the earliest armour. However, embryology of dental structures in living vertebrates reveals that dentine derives from neural crest (Hall, i 983 ; Lumsden, 1988), whereas the ordinary lateral-line system and the electroreceptors derive from placodal tissues (Northcutt, I986).

The fossil record shows various early states that might support the suggestion that all layers of the odontodes arose simultaneously (Halstead, 1987). Whereas, cephalochordates possess integumentary ciliated sensory elements, but lack supportive tissues, suggesting that evolution of sensory elements may have preceded evolution of dermal supportive tissues, the development of odontoids allows two hypotheses. The first is that sustentacular regions calcified simultaneously with, but independently of, the vertebrate mechanoreceptive and electroreceptive sense organs, perhaps in response to an indepcndent demand for calcium storage and increased armouring (Romer, I933). However, this provides no explanation of why dentine derives from neural crest. Alternatively, sensory organs developed prior to the evolution of dentine and enameloid. According to this interpretation, the latter tissues evolved from supportive cells in functional association with the sensory elements and initially served as transduction enhancers for sensory stimuli (Northcutt \& Gans, r983; Gans \& Northcutt, r983).

It is theorized that the transduction-enhancing odontoblasts of phylogenetically early dentine cither derived from neural elements or from supportive cells associated with primitive electroreceptors. The capacity of odontoblasts to deposit extracellular hydroxyapatite around the receptor cells affected the dielectric properties of their surroundings and thereby enhanced sensory capacity. Decision on whether the odontoblasts stemmed from supportive cells of neural crest origin or from unicellular electrosensory units remains uncertain and would be aided by re-examination of the pattern seen in the integument of more Recent and fossil fishes. Both hypotheses accord with known evidence, but involve postulates differing in number and kind. Dentine may have been the earliest calcified tissue, the enameloid layer arising almost simultaneously, being either modified dentine or resulting from epithelial ameloblasts (Kemp, 1984; Halstead, 1987). So-called 'true' enamel, capping scales and teeth of amphibians, reptiles and mammals, is a product of epidermally derived ameloblasts induced by the underlying neural-crest tissue (Meinke \& Thomson, 1983; also Prostak \& Skobe, 1986).

Why did such integumentary organs arise in the first place? The hypothesis is that electroreception could detect chemoelectric gradients associated with dense pockets of small organic particles (Kalmijn, I 974); the second hypothesis is that electroreception could detect larger individual prey animals. Although the first hypothesis is possible, there is no evidence that any living vertebrate is sensitive to such fields; also, dense pockets of organic material would be more likely to occur in relatively stagnant ponds rather than in potentially turbulent shallow marine environments. In contrast, heart action, gill perfusion and other muscular activity of invertebrates establish characteristically cyclic field effects of varying strength (which are greater if the action occurs in brackish rather than in fresh waters).

Even weakly developed electroreception is better than visual detection of organisms in silty waters or nocturnally. However, the initial utilization of electroreception 
remains an important consideration. In modern vertebrates, electroreception works in association with a number of behaviours, such as prey and predator detection, social communication, orientation to the environment and possibly navigation. Of that list, prey detection represents the most ubiquitous role and that in which a minor detecting capacity would immediately incur selective advantage. Hence, electroreception represents an obvious primary candidate for the first sensory stage of vertebrate predators.

A fact not immediately supportive of this hypothesis is the absence of electroreception in hagfish, although it is present in lampreys (Bodznick \& Northcutt, 1981; Bullock et al., 1982, 1983; Fernholm, 1985). Two hypotheses may account for this observation in the present context. First of all, it is possible that electroreception arose after the origin of hagfish; as these animals lack calcified tissues, one might posit that electroreception arose after their separation from the craniate line. More likely, the seemingly derived hagfish lost electric organs as well as dermal bone; certainly, electric organs have been lost several times in the lineages of fishes. This hypothesis may be supported by the recent report that the enamel proteins of higher vertebrates are immunologically similar to the proteins of the intercellular material in the 'teeth' of hagfish (Slavkin et al., I 983).

\section{(1о) The origin of bone}

This leads to a discussion on the origin of true bone, first seen in the fossil record as the dense, deepest (as well as the spongy intermediate) layer of the scales. Classical hypotheses for bone formation assume that evolutionarily bone is the primary calcified tissue. The literature suggests that bone is used $(a)$ as an osmotic barrier, $(b)$ for the storage of calcium salts, $(c)$ to generate negative buoyancy, and $(d)$ as a defensive armour (Romer, 1933). The first view is unlikely as fishes leave the much larger gill surface unprotected. Salts could be stored anywhere; the calcium-storage hypothesis does not explain the complex scale architecture. Negative buoyancy similarly does not require a complex architectural design. Scalation would have to achieve substantial thickness before having a significant role as armour; its inertia then incurs a substantial cost in hampering evasive movements. Evidence from the fossil record suggests that the odontode pattern derived earlier in ontogeny than the deeper endoskeleton (MoyThomas \& Miles, 197I). This suggests that this sequence may represent a phylogenetic recapitulation and boosts the concept that the earliest bone was integumental and associated with electroreception.

The anterior concentration of the sensors of bilateral animals provides them with directional information (including the position of predators and perhaps conspecifics). It also facilitates receipt and co-ordination of information about the position of prey relative to the mouth. Bilateral placement of anterior sensors permits triangulation, and dorsal-ventral placement permits positioning the target in three-dimensional space. Symmetrical placement of sensory cells allows modification of the integrating system and projections of their inputs along a cortical surface facilitates comparisons; it permits common mode rejection of signals that reflect far-distant events and enhancement of signals from sources closer to the organism.

Association of the initially forming dentine with an electroceptive sense suggests that the bone of the primitive integumentary denticles originated as a stabilizing tissue. The phylogenetically secondary deposition of hydroxyapatite crystals as bone in the dermis 
allowed maintenance of the position of the sensory elements (Northcutt \& Gans, I983). This scenario may account for the well-defined patterns of pits and lateral-line canals in many fishes, the architecture of which was probably established by the sense organs harboured by the bones. It is likely too that the outward shift of the paired sensory organs, detecting light, pressure and chemical cues, reflects increased size; also, calcification led to a denser integument including hydroxyapatite, forcing externalization of the sense organs. In parallel, predation clearly established the adaptive value of recording the direction of the incident sensory information, as well as of its magnitude.

Increased size also required a true dermis, and the fascial network of angled collagen fibres lying deep to the dermis and stiffening the trunk, transmitting the action of some muscular components and yet permitting bending (Gutmann \& Bonik, I98r; Wainwright, 1983). Ossification of the integument proceeded by the deposition of crystalline hydroxyapatite along pre-existing collagenous matrices and apparently involved simultaneous calcification of the internal framework of head and (later) trunk. Witness the calcified head cartilage in the earliest-known (Ordovician) heterostracan fishes (Denison, 1967), Perichondral bone in the ostracoderm head (Moy-Thomas \& Miles, I $97 \mathrm{I}$ ) and even traces of calcification in some lamprey head cartilages (Bardack \& Zangerl, 1972). In the much later gnathostomes, this initial calcification apparently extended interiorly, leading to the development of vertebrae and of the truly segmented posterior portion of the braincase. With calcification of a significant portion of the integument, the armour developed obvious defensive potential. Also, it provided calcium and phosphorus storage, which may have facilitated invasion of environments such as intermittently brackish waters, in which $\mathrm{Ca}^{2+}$ varies unpredictably, and ultimately of fresh water and land.

The exact sequence of integumentary and endoskeletal ossification remains unclear. Similar problems beset the relative times of origin of cartilage and bone. Cartilage in the pharyngeal region essentially is an energy-storing (and supportive) component of a gill system vital for ventilatory inspiration. Until the advent of cartilage, animals relied on integumentary gas exchange which could have been limited by any ossification of the skin. This makes it plausible that the cartilage of the gill apparatus probably preceded dermal bone in phylogeny. Calcification of cartilage and endoskeletal bone arose later (Kemp \& Westrin, 1979; Kemp, I984).

\section{(I I) Excretion and reproductive strategies}

The evolution from a protochordate to a vertebrate level must have involved at least one other major transition. In protochordates, and perhaps in prevertebrates, the excretory and gonadal system was associated with pharyngeal blood vessels and branches of the coelom; the effluent discharged directly into the pharyngeal lumen, a region regularly perfused with water. Flagellated tubules connected the coelomic to the pharyngeal space. With the loss of the initial association of the excretory system with the pharyngeal slits, there appears retention and possible enhancement of its association with the posterior coelom (Leake, 1975). In parallel, one sees complex modifications shortening the vertebrate pharynx and elongation of the posterior visceral cavity by development of folded gill surfaces and the pharyngeal modification for predation (Hickman \& Trump, r 969). 
The excretory organs of Branchiostoma consist of sets of cyrtopodocytes rather than solenocytes as once claimed (Welsch, 1975). There is also the organ of Hatschek, lying to the left of the rostral portion of the notochord (Welsch, 1975). The cyrtopodocytes lie lateral to the top of the secondary branchial bars, which form only at metamorphosis. (Only the primary branchial bars are assumed to be homologous between cephalochordates and vertebrates.) Perhaps the transition to vertebrates involves restructuring of the excretory system and its shift to an equivalent but more posterior position, along the roof of the coelomic cavity. Paired longitudinal excretory ducts are a vertebrate characteristic. The intimate association of the genito-excretory system with the coelomic cavity (seen in Recent agnathans and larval and embryonic amphibians) suggests that vertebrate kidneys (and gonads) once were in continuity with the coelom and coelomic pore (Starck, 1978).

The vertebrate kidney as such is analogous rather than homologous to the excretory organs of cephalochordates (Starck, I978). However, the structure of cyrtopodocytes of cephalochordates is similar to the podocytes of vertebrates. Hence, one may posit homology on the cellular rather than the organ level, equivalent to the shift of chromaffin tissue to the adrenal medulla. Perhaps the capacity to form podocytes was a potential of the entire dorsal portion of the non-segmented mesoderm, or developed in the pharynx and later shifted into the coelom, as the pharynx shrank and the coelom increased in size.

Excretory tissue antedates vertebrate origins. Its shift from pharyngeal to visceral region involved both developmental and functional factors. Developmentally, the shift may have been relatively minor as the zone incorporating the excretory tissue derives from the floor of the coelomic mesothelium in amphioxus and the subsomitic mesomere in vertebrates. Also, the posterior portion of the pharynx is close to the pronephric region, which in ammocoetes retains both glomerular tufts and ciliated connexions to the coelom.

The posterior shift of excretory tissue probably led to the formation of collecting ducts to the exterior (and later allowing discharge of the sperm and ova via the cloaca rather than genital pores; Starck, I978; Janvier, 198I). This positional shift of excretory tissue presumably paralleled the restructuring of the pharynx. Formation of a true gill system coincided with the loss (or non-formation) of secondary branchial bars next to which the cyrtopodocytes lie. Indeed, neural crest, which has a developmental role in restructuring all other shared-derived aspects of the vertebrate pharynx, may also participate in kidney formation. Transplanted head neural crest inhibits the formation of trunk kidney tissue, with which it is ordinarily not involved (Jacobson, I987). Perhaps this is a retention of the capacity of the neural crest to reorganize the pharynx.

The shift of excretory tissue may also reflect the role shift of the circulation. The vascular spaces of Branchiostoma lack endothelial lining and the excretory cells are concentrated in the pharynx, one of the few places regularly passed by most of the blood. With the volumetric shift of pharyngeal and coelomic spaces reflecting the advent of predation, an increase in the number of podocytes accompanied their shift to the zone dorsal to the coelom; however, this shift probably followed the formation of a closed (endothelium lined) circulation. Association of podocytes in glomerular capillary tufts increased excretory surface beyond the very limited capacity of the system in 
Branchiostoma (Binyon, 1979). Clustering (a developmentally obvious shift reflecting invagination of the coelomic filtering surface) and development of ducts draining all kidney tissues loosen their association with the visceral space (which is still seen in ammocoetes and larval amphibians; Leake, 1975). Such secondary tendencies are seen also in various invertebrates.

Consequently, the excretory changes correlate with the other demonstrated traits of early vertebrates, namely increase in size and shift to predation. All require a parallel increase in excretory capacity. Larger amphioxus have more pharyngeal slits and hence more secondary bars and cyrtopodocytes. The increase in the volume of vertebrates required an equivalent increase of kidney tissue, independent of the pharyngeal length. The shift from suspension feeding to predation further loaded the excretory system. Food ingestion and hence digestion became intermittent and the digestion of proteins produced complex molecules. The transition to vertebrates also demanded anaerobic glycolytic metabolism (Ruben \& Bennett, 1980). Vertebrate spurt capacity is about ten times greater than that of protochordates; this clearly requires an increased excretory capacity for metabolic waste. The excretory tissue had to meet peak demands, no longer responding only to constant levels of waste and $\mathrm{pH}$. Hence, the kidney organization changed coincident with the far-reaching shifts from suspension feeding to predation.

Kidneys maintain the internal environment by discharging water entering by osmosis. The increased filtration capacity of most vertebrate kidneys reflects the transition of the earliest vertebrates to fresh water; indeed, this has been cited as evidence for the freshwater origin of these animals (Marshall \& Smith, 1930). More likely the osmotic system arose in an unstable marine environment; for instance, estuarine habitats show sudden and unpredictable changes of salinity, reflecting river flow which is modified by rainfall hundreds of kilometres distant (Northcutt \& Gans, 1983). In short, increased kidney capacity, suitable for occasional overload, is required for several quite-distinct roles, and its development may have been synergistic for these. (All of this argument encounters some problems with the physiology of the hagfish kidney; although structurally similar to the lamprey pattern, it differs among other factors in the absence of pressure filtration; Riegel, 1986).

The new kidney tissues are associated with the archinephric discharge ducts that drain their products. These ducts initially may have drained the coelomic fluid (from the pronephric funnels) to the cloaca. Alternatively, there is the concept of a segmentally organized kidney (a pronephric stage) that led to the initial formation both of sets of podocytes and of tubules in each unit: see the segmental pronephrostomes in vertebrates. Presumably the ducts arose in association with the increased visceral volume and were co-opted by the reproductive system: both excretion and reproduction derive advantages from organized discharge of materials initially associated with the coelomic space.

Elongation of the visceral cavity increased the space potentially available for the functional specialization of the kidneys. The advent of tubules provided sites for other kinds of cells, respectively involved in selective resorption from the original filtrate and secretion of particular metabolites. The time course of these changes remains unclear, so they are omitted from discussion of the initial shifts to the vertebrate form.

It is likely that the reproductive pattern of the prevertebrates was similar to that of present protochordates, involving synchronized gonadal maturation and a more-or-less 
simultaneous discharge of genital products. Textbook considerations concentrate on the shift of the gonads into the true visceral space and discharge of germ-cells via the tubules of the excretory system. Protochordate eggs have variable amounts of yolk; most are isolecithal. However, yolk content may be plastic. The striking difference between the petromyzontid isolecithal and myxinoid telolecithal eggs has been emphasized (Hardisty, 1979; Mallatt, 1985); however, that between mesolecithal thaliacean eggs and the isolecithal eggs of many other protochordates is less well known (cf. Young, 198I). In contrast, the eggs of most recent anamniote gnathostomes (except chondrichthyes and Latimeria) are mesolecithal.

The estuarine habitat remains critical in explaining the evolution of vertebrates. River biotopes involve protracted unidirectional currents. Living aquatic animals can only occupy them if they are parthenogenetic (or otherwise capable of vegetative propagation), or have provision for mate encounter and potential for fertilization therein. Localization of potential mates may have been another task of the evolving vertebrate distance-receptors. Further by-products of the shift to fresh water was the need for mate recognition, embracing a more specific kind of selection, indeed for some kinds of accelerated evolutionary change.

\section{THE COMBINED SEQUENCE}

It is now possible to summarize the relative timing of changes in all of the organ systems and presumed environments and to develop a proposed evolutionary sequence.

Chordates arose from a line of relatively small, ciliated, suspension-feeding, freeliving forms that had an epidermal nerve plexus and metamorphosis. Ancestors were possibly littoral in the early to mid-Cambrian times (coastal regions expanded rapidly as the continents split during the early Palaeozoic era; Bambach, i 980). Analysis of invertebrate fossils suggests reaction to more effective predation at this time in evolution.

The first change of prechordates was postmetamorphic, involving development of a notochord that stiffened the base of a caudal appendage. Sudden movement due to contraction of associated muscles reduced attack-effectiveness of predators. Firm anchoring of the notochord to the body further stiffened the appendage and provided for its elastic return to the original position.

Secondary modifications allowed periodic movements of the appendage, generating faster locomotion, also advantageous in feeding. This began with extension of the muscular segmentation and associated concentration of motor neurons from the basal site of its initial induction toward the caudal tip. During phylogeny, the basal site (marked by the anterior tip of the notochord and associated muscles and nerves) progressed anteriorly along the dorsal surface, involving ever more of the bilaterally symmetrical trunk in locomotion. With shift of propulsion from cilia to muscle, the integrative and motor pathways of the epidermal nerve plexus concentrated into a middorsal nerve plate. This invaginated into a hollow tube (nerve cord) housing the cell bodies of the integrative and motor nerons. Sensory receptors became concentrated along the anterior region of this plate. A second metamorphosis was associated with increased size and reorganization of the pharynx, doubling of pharyngeal bars, development of excretory tissue, and formation of an atrium with subpterygial coughing muscles. 
These animals showed the chordate level of organization with floating ciliated larvae which then metamorphosed into motile adults propelling themselves with a notochord and associated muscles. Surviving protochordates (mostly ascidian tunicates) suggest that some early chordate lines independently become sessile, whereas others became complexly colonial through secretion of large extraorganismal mucoid constructions.

Next occurred an experimental radiation of amphioxus-like animals. Heterochrony delayed their secondary metamorphosis to a gradually larger size. This and increased activity reduced adequacy of diffusional ventilation. As the larger individuals were still premetamorphic, they showed neither secondary pharyngeal bars nor an atrium. The subpterygial musculature (retaining dorsal root innervation and later referred to as branchiomeric) became associated with the primary pharyngeal bars. Contractions of the pharynx pumped more water, thereby increasing pharyngeal gas exchange.

Embryonic connective tissues of neural-crest origin contributed chondromucoid to the collagenous frame of the primary pharyngeal bars, permitting water inflow by clastic recoil. The increased number of motor neurons for the branchiomeric muscles and the new gas-detecting sensory systems extended the CNS anteriorly, forming a 'new' brain, differing in organization from the spinal cord. The branchial arch epithelia capillarized and folded into gills facilitating gas exchange. The circulation closed, endothelia invaded, and the separate contractile bulbs were replaced by a single heart. Podocytes and the discharge of genital products became associated with the coelom. Finally, the gonads matured and the second metamorphosis was suppressed. These changes increased gas exchange, and allowed further developments facilitating prolonged and organized locomotory patterns and larger size.

At this period, such prevertebrate animals moving along the bottom of the coastal shelves presumably were protoadapted for ingesting accidentally contacted unarmoured prey. The longitudinal axial muscles pushed prey into the pharyngeal opening and the circular branchiomeric muscles forced the prey via the pharynx into the gut. The earliest phylogenetic stages might have recognized incidentally contacted prey by chemical or mechanical cues. However, increase of detection-distance, improved directionality and more rapid response would be advantageous; the latent electroreceptive capacity initially provided these. Change to more regular predation led to restructuring both of pharyngeal mechanics and of posterior viscera, the development of an oesophagus-stomach for storage and initial breakdown of food, muscular (peristaltic) rather than ciliary transport through the gut (controlled by neural-crestderived motor neurons), and extracellular digestion.

The benefits of predation may have allowed a very rapid series of phylogenetic changes permitting shift of adults from being occasional predators into obligate ones. Patches of external and specializing sensory neurons concentrated near the front of the animal and became encapsulated, thereby facilitating directionality; their embryonic stage was homologous to the modern placodes. Centrally, the alar region of the brain became modified and hypertrophied; evaginations reached toward some placodal regions, and integrative components linked the increasing sensory inputs with the motor systems modified to control the hypertrophied branchiomeric musculature. This must have marked a major modification of the sensory aspects of a nerve cord modelled on Branchiostoma, much of which is restricted to the integrative and motor functions of the segmented axial musculature. Late in development, the brain and anterior 
sensory organs were encapsulated hydrostatically anterior to the tip of the notochord. Hence, prior stages of ontogeny show minimal restructuring; however, the head extends forward, dorsal to the level of the first two pharyngeal bars.

This stage sees the initial deposition of hydroxyapatite as pustular, dentine-like reinforcements of individual processes of electrosensory cells, the directional dielectric properties of hydroxyapatite increasing the ability of the sensors to detect electric-field effects. Phylogenetically next, there developed larger, more organized, dentinous and enameloid-covered pustules and then dermal denticles, as the original unicellular receptors combined into multicellular arrays. The resulting animals retained ciliated suspension-feeding larvae, but at metamorphosis expanded their sensory capacity by differentiating paired, external, distance-sensing arrays. The freely swimming postmetamorphic forms were presumably benthic, ingesting whole, small, unarmoured prey by a "push into the pharynx and constrict" pattern. The first sensory systems could have been simple, as the early Cambrian showed few predators at this level so that defensive mechanisms of potential prey (predator detection, avoidance and armouring) were still minimal. This phyletic stage exhibited most of the characteristics by which the vertebrates are now defined.

The head probably formed intrinsically as a neomorph anterior to the otic region at which the basic mesodermal segmentation of vertebrates begins and which presumably marks the front of the ancestral animal. The segmentation of the somitomere musculature is distinct from that of the trunk; it mainly reflects the branchial segmentation, involving gill-slits and bars, differing from and antedating the mesodermal somitic segments. The paired external sense organs-nose, eye, ear, electoreception and lateral line - are independent and do not represent remnants of a past topographic sequence. The anterior connective tissues of the head derive from initially unsegmented neural crest.

The capacity to sequester and deposit hydroxyapatite crystals, initially generated in the skin by odontoblasts of the neural crest and later induced in the overlying ectodermal ameloblasts, also passed to cells forming the deeper endoskeletal connective tissues of the head and later on to sclerotomal and dermatomal components of epimeric mesoderm. The evolution of a dermal cuirass maintained the spatial position of the sensors. Sensory projections were refined and the internal 'mapping' presumably improved. The central projections of several sensory modalities gradually became coordinated by analogous layering over central cortices.

The initial 'dermal bone' formed at metamorphosis. Later in phylogeny there was internal ossification of the braincase and sensory capsules. Ossification is a critical event, not so much in terms of vertebrate history but in our direct understanding of it. This is the time at which one begins to see entire fossils, rather than bits of broken bone. As ossification initially was metamorphic, the earliest forms most likely had all the major vertebrate sense organs and the characteristic subdivisions of the brain. Presumably the fossils of these predators represent animals with determinate growth completed by the time of metamorphosis and ossification (Moy-Thomas \& Miles, I97 I). Appositional growth of individual elements, permitting increase of skeletal size, represents a later stage in phylogeny. The changes in blood $\mathrm{pH}$ associated with spurts of intense exercise seem to have affected the skeletal tissues seen in vertebrates (Ruben $\&$ Bennett, 1981 ). 
Dermal armour let the vertebrates develop further feeding specializations. Examples are the bilaterally acting jaws of myxinoids, and the symmetrical jaw pattern of the gnathostomes; both incorporated a potential for more effective grasping, killing and ingestion of prey. At this stage, the adults could leave the substrate and predate pelagic rather than littoral sessile prey.

\section{V1. PROBIJEMS ANI THEORY}

The scheme proposed attempts to overcome some major practical difficulties confronting students of phylogeny. The fossil record is limited and many critical questions remain to be considered. We lack important physiological data on many of the extant animals closest to the transitional vertebrate ancestors. Indeed, it is worth restating that much of the developmental information in the preceding account is based on data from elegant studies pursued at the end of the nineteenth and beginning of the twentieth century, which utilized technical methods far cruder than more recent ones. The capacity, for example, to trace cell lineages by use of monoclonal antibodies and signature proteins presents a new field, as yet applied to relatively few forms and only now for some critical groups.

A more important point, the source of much confusion in the interpretation of phylogeny, is best expressed Alfred Romer's phase (in lecture) that "animals cannot afford to sit around in their time being ancestors; they must go off and make a living if they wish to survive". Thus, the present descendants of their early ancestral stages survived because they occupied and successfully maintained themselves in favourable niches. Here they outperformed members of later radiations that replaced the early groupings. Presumably, they represent highly specialized forms rather than broadly capable generalists.

The dichotomy expressed by myxinoids and petromyzontids represents precisely this kind of situation. These forms show different modes of ontogeny, myxinoids generating large-yolked eggs which permit maternal contribution to development sufficient to obviate metamorphosis, whereas the ammocoete larvae of petromyzontids have independently invaded a niche superficially like that of Branchiostoma. The dichotomy, extending into the adult condition, may explain such profound differences as those in their circulation (Lewis \& Potter, I982; Wells et al., I 986) and kidney function (Riegel, 1986).

Many of the changes, such as the concentration of sensory endings and the amplification of gill surfaces, involve epigenetic developmental processes, conceptually similar to those termed physiological adaptations (Prosser, r 958). The capacity of cells and tissues to generate organs or carry out processes that often match environmental circumstance hardly is independent of adaptive selection. Indeed the level of matching that such processes generate, documents that the capacity of the cells to track the environment cannot be random; it is under genetic control at a higher level and results from past selection (Cans, I966, 1974, 1988).

Uncertainty suggests a multiplicity of phylogenetic scenarios. Selection among these requires a broad analysis, exploring multiple organ systems, multiple developmental stages, as well as their ecological aspects, all in a phylogenetic framework. The analysis must test conclusions from different approaches against each other. Some such arguments are detailed here as examples of this approach. Other arguments have been 
omitted or abbreviated; this leads to a kind of shorthand presentation, of conclusions rather than step-by-step analyses.

In each case, all phylogenetic scenarios found in the literature or generated in discussion have been examined. The rule of parsimony permitted selection of scenarios requiring the fewest currently undocumented assumptions. It proved unnecessary to posit major and complex genetico-developmental transitions without observed phenotypic intermediates known to be viable. Saltational arguments are rejected, not because they are impossible but because they proved unnecessary. If parsimony is to be utilized in the generation of classifications and as a general explanatory principle in scientific investigation, saltation can only be used as an explanation after the potential for minor stepwise modifications has been disproved.

It is hoped that this study documents that phylogenetic scenarios allow the establishment and test of phylogenetic processes, the steps of which are not otherwise approachable. They do not generate the absolute truth or certainty, or some ideal intellectually satisfying state, any more than do other approaches of modern science. However, they do generate sets of probability statements, establishing likely limiting conditions. Most are testable by consideration of existing information that might falsify them. Others will remain on record until they can be tested by new information on behavioural and physiological conditions in Recent animals and by an improved understanding of fossils. Such scenarios encourage one to seek data not previously considered pertinent. Sometimes such data are found in the literature. At other times one has to ask the animal; hence scenario generation spurs more informed observation. The most important benefit of scenario generation may be the improved understanding of the biology of animals, Recent and ancestral.

\section{SUMMARY}

Vertebrates lack an epidermal nerve plexus. This feature is common to many invertebrates from which vertebrates differ by an extensive set of shared-derived characters (synapomorphies) derived from the neural crest and epidermal neurogenic placodes. Hence, the hypothesis that the developmental precursor of the epidermal nerve plexus may be homologous to the neural crest and epidermal neurogenic placodes. This account attempts to generate a nested set of scenarios for the prevertebrate-vertebrate transition, associating a presumed sequence of behavioural and environmental changes with the observed phenotypic ones. Toward this end, it integrates morphological, developmental, functional (physiological/behavioural) and some ecological data, as many phenotypic shifts apparently involved associated transitions in several aspects of the animals. The scenarios deal with the origin of embryonic and adult tissues and such major organs as the notochord, the CNS, gills and kidneys and propose a sequence of associated changes. Alternative scenarios are stated as the evidence often remains insufficient for decision. The analysis points to gaps in comprehension of the biology of the animals and therefore suggests further research.

\section{ACKNOWLEDGEMENTS}

This manuscript was begun jointly with R. Glenn Northcutt and I appreciate his comments on the early portions. I thank F. C. Billett, Q. Bone, D. Carrier, H. R. Duncker, H. Fox, J. Hanken, N. E. Kemp, J. Mallatt, P. F. A. Maderson, D. B. Wake and P. W. Webb for comments on instars of the manuscript and many colleagues for the aid and discussions that led to it. Ms. Katherine Vernon helped with typing and the literature searches. It 
is a pleasure to acknowledge that this is one of a number of studies that could be completed while C. G. held a guestprofessorship at the Department of Biology of the University of Antwerp (UIA). He also wishes to express appreciation for the staff of the L aboratoire Arago at Banyuls-sur-Mer for hospitality and facilities that permitted observations on living Branchiostoma. Supported by NSF grant BSR-850940 to Gans.

\section{REFERENCES}

Aidripge, R. J., Briggs, D. E. G., Clarkson, E. N. K. \& Smith, M. P. (1986). The affinities of conodonts - new evidence from the Carboniferous of Edinburgh, Scotland. Lethaia 19, 279-291.

Ariëns Kappers, C. U., Hurfe, C. (G. \& Crosby, E. C. (1936). The Comparative Anatomy of the Nervous System of Vertebrates, including Man. Macmillan, New York.

ARnot.d, G. P. \& WeIhs, D. (1978). The hydrodynamics of rheotaxis in the plaice (Pleuronectes platessa L.). Yournal of Experimental Biology 75, 147-169.

ATEMA, J. (1971). Structure and functions of the sense of taste in the catfish (Ictalurus natalis). Brain Behavior and Evolution 4, 273-294.

Ax, P. \& Ax, R. (1969). Eine Chorda intestinalis bei Turbellarien (Nematoplana nigrocapitula Ax) als Model für die Evolution der Chorda dorsalis. Abhandlungen der mathematisch-naturwissenschaftlichen Klasse der Akademie der Wissenschaften zu Mainz (5), 135148.

BaAtrup, E. (1981). Primary sensory cells in the skin of amphioxus (Branchiostoma lanceolatum (P)). Acta 7oologica 62, $147-157$.

BaAtRup, E. (1983). Ciliated receptors in the pharyngeal terminal buds of larval Lampetra planeri (Bloch) (Cyclostomata). Acta Zoologica 64 (I), $67-75$.

Bainbridge, R. (1961). Problems of fish locomotion. In Vertebrate Locomotion. Zoological Society of London Symposia 5, $129-153$.

BaInssk, B. I. (1981). An Introduction to Embryology, 5th ed. W. B. Saunders, Philadelphia.

Bambach, R. K. (1980). Before Pangea: The geographies of the Paleozoic world. American Scientist $68,26 \cdots 38$.

BARDACK, D. \& Zangeri, R. (1972). Lampreys in the fossil record. In Biology of the Lampreys, vol. I (ed. M. W. Hardisty and I. C. Potter), pp, 67-84. Academic Press, London.

Barnes, R. D. (I966). Invertebrate Zoology. W. B. Saunders, Philadelphia,

Barrington, E. J. W. (1965). The Biology of Hemichordata and Protochordata. Oliver and Boyd, Edinburgh.

Baskin, D. G. \& Detmers, P. A. (1976). Electron microscopic study on the gill bars of Amphioxus (Branchiostoma californiense) with special reference to neurociliary control. Cell and Tissue Research 166, $167^{-1} 7^{8}$.

BeEre, W. (1934). Half Mile Down. Harcourt, Brace, New York.

Birrit.., N. J. (1950). The Tunicata, with an Account of the British Species. Ray Society, London.

Berrill, N. J. (1955). The Origin of Vertebrates. Clarendon Press, Oxford.

Bigelow, H. D. \& Schroeder, W. C. (1948). Fishes of the Western North Atlantic, vol, I. Sears Foundation for Marine Research, Yale University.

Binyon, J. (1979). Branchiostoma lanceolatum - a freshwater reject? Fournal of the Marine Biological Association of the U.K. 59,61-67.

Blakl, R. W. (1983). Fish Locomotion. Cambridge University Press, Cambridge.

Bitght, A. R. (1977). The muscular control of vertebrate swimming movements. Biological Reviews 52, I 8 I-2 18 .

Bodznick, D. A. \& Northcutt, R. G. (1980). Segregation of electro- and mechanoreceptive inputs to the elasmobranch medulla. Brain Research 195, $3^{1} 3^{--32}$.

Bonznick, D. A. \& NorThcut', R. G. (1981). Electroreception in lampreys: evidence that the carliest vertebrates were electroreceptive. Science, New York 212, 465467.

Bone, Q. ( $1985 a)$. Synaptic relations in the atrial nervous system of amphioxus. Quarterly Yournal of Microscopical Science 99, 243-261.

Bone, Q. $(1985 b)$. The asymmetry of the larval amphioxus. Proceedings of the Zoological Society of London $\mathbf{1} 30$, 280-293.

Bone, Q. (1959a). Observations upon the nervous system of pelagic tunicates. Quarterly Yournal of Microscopical Science 100, $167-18 \mathrm{r}$

Bone, Q. (1959b). The central nervous system in larval acraniates. Quarterly fournal of Microscopical Science roo, 509527

Bone, Q. (1960a). The central nervous system in amphioxus. Journal of Comparative Neurology $1 \mathbf{5 5}, 27-64$.

Bone, Q. (1960b). The origin of the chordates Zoological Journal of the Linnean Society of London 44, $252-269$.

BONE, Q. (1960c). A note on the innervation of the integument in amphioxus, and its bearing on the mechanism of cutaneous sensibility. Quarterly fournal of Microscopical Science ror (3), 371-379. 
Bone, Q. (r96I). The organization of the atrial nervous system of amphioxus (Branchiostoma lanceolatum (Pallas)). Philosophical Transactions of the Royal Society of London B 243, $241-269$.

Bone, Q. \& BEst, A. C. G. (1978). Ciliated sensory cells in amphioxus (Branchiostoma). Fournal of the Marine Binlogical Association of the U.K. 58, 479-486.

Bune, Q. \& Marshall, N. B. (1982). Biology of Fishes. Blackie, London.

Bone, Q. \& Ryan, K. P. (1978). Cupular sense organs in Ciona (Tunicata: Ascidiacea). Fournal of Zoology, London I86, $417-429$.

Bonik, K., Grasshoff, M. \& Gutmann, W. F. (1976). Die Evolution der Tierkonstructionen. III. Vom Gallertoid zur Coelomhydraulik. Natur und Museum ro6 (6), i $78-188$.

Braconnot, J.-C. (1970). Contribution à l'étude des stades successifs dans le cycle des tuniciers pelagiques doliolides. I. Les stades larvaire, oozooide, nourrice et gastrozooide. Archives Zoologie Expérimentale et Générale III, 629-668.

Brien, P. (1948). Embranchement des tuniciers. In Traité de Zoologie (ed. P. P. Grassé), vol. 11, pp. 553-894. Masson, Paris.

Briggs, D. E. G., Clarkson, E. N. K. \& Aldridge, R. J. (1983). The conodont animal. Lethaia 16 (1), I-I4.

Brun, R. B. \& Garson, J. A. (1984). Notochord formation in the Mexican salamander (Ambystoma mexicanum) is different from notochord formation in Xenopus laevis. Fournal of Experimental Zoology 229 (1), $235^{-240 .}$

Bullock, T. H., Bonznick, D. A. \& Northcutt, R. G. (1983). The phylogenetic distribution of electroreception: Evidence for convergent evolution of a primitive vertebrate sense modality. Brain Research Reviews 6, 25-46.

Bullock, T. H. \& Horridge, G. A. 1965. Structure and Function in the Nervous Systems of Invertebrates, a vols. W. H. Freeman, San Francisco.

Bullock, T. H., Northcutt, R. G. \& Bodznick, D. A. (1982). Evolution of electroreception. Trends in Neurosciences 5 (2), 50-53.

Carter, G. S. (1971). Structure and Habit in Vertebrate Evolution. Sedgwick and Jackson, London.

ClaRk, R. B. ( 1964$)$. Dynamics in Metazoan Evolution. The Origin of the Coelom and Segments. Oxford University Press, Oxford.

Coghili. G. E. (1914). Correlated anatomical and physiological studies of the growth of the nervous system of Amphibia. Gournal of Comparative Neurology 24, $16 \mathrm{I}-234$.

Damas, H. (1944). Développement de Lampetra. Archives de Biologie Liège 55, 1-284.

Darwin, C. (1871). The Descent of Man and Selection in Relation to Sex. J. Murray, London.

Dawson, J. A. (1963). The oral cavity, the 'jaws' and the horny teeth of Myxine glutinosa. In The Biology of Myxine (ed. A. Brodal and R. Fänge), pp. $231^{-255}$. Universitetsforlaget, Oslo.

Denison, R. H. (1947). The exoskeleton of Tremataspis. American fournal of Science 245, 337-365.

Denrson, R. H. (196r). Feeding mechanisms of Agnatha and early gnathostomes. American Zoologist $1,177^{-1} 8 \mathrm{I}$.

Denison, R. H. ( 1967). Ordovician vertebrates from western United States. Fieldiana, Geology I6 (5), 135-192.

Denison, R. H. (1973). Growth and wear in the shield in Pteraspididae (Agnatha). Paleontographica A $143,1-10$.

Drach, P. (1948). Embranchement des céphalochordés. In Traité de Zoologie (ed. P.-P. Grassé), vol. 11 , pp. $93^{1-1037 . ~ M a s s o n, ~ P a r i s . ~}$

Eakin, R. M. \& Westfall., J. (1962). Fine structure of photoreceptors in amphioxus. Fournal of Ultrastructural Research 6, (5-6), 531-539.

Eaton, T. H. (1970). The stem-tail problem and the ancestry of chordates. fournal of Palentology 44 (5), 969 979.

Eidredge, N. (1979). Cladism and common sense. In Phylogenetic Analysis and Paleontology (ed. J. Cracraft and N. Eldredge), pp. 165-198. Columbia University Press., New York.

Eldredge, N. \& Cracraft, J. (1980). Phylogenetic Patterns and the Evolutionary Process. Columbia University Press, New York.

EwerT, J. P. (1980). Neuroethology. Springer-Verlag, Berlin.

Fernholm, B. ( $\left(9^{8}\right)_{5}$ ). The lateral line system of cyclostomes. In Evolutionary Biology of Primitive Fishes (ed. A. Gorbman, R. Olsson and R. E. Foreman), pp. I I $3^{-122}$. Plenum Press, New York.

Finger, T. E. (1983). The gustatory system in teleost fish. In Fish Neurobiology (ed. R. G. Northcutt and R. E. Davis), vol. 1, pp. 261-284. University of Michigan Press, Ann Arbor.

FLood, P. R. (1966). A peculiar mode of muscular innervation in amphioxus. Light and electron microscopic studies of the so-called ventral roots. Fournal of Comparative Neurology 126, $181-218$.

FLOOD, P. R. (1968). Structure of segmental trunk muscle in amphioxus with notes on course and endings of socalled ventral nerve fibres. Zeitschrift für Zellforschung und microscopische Anatomie 84, 389-416.

Ford, P. (1949). The origin of the segmental musculature of the tail of the Axolotl (Ambystoma). Proceedings of the Zoological Society of London 119 (3), $609-632$. 
FOREY, P. L. (1984). Yet more reflections on Agnathan-gnathostome relationships. Fournal of Vertebrate Paleontology 4, 340-343.

Franz, V. (1927). Morphologie der Akranier. Ergebnisse der Anatomie und Entwicklungs-Geschichte 27, 464-692.

Gans, C. (Ig66). Some limitation and approaches to problems in functional anatomy. Folia Biotheoretica 6 , $41^{-5}-50$.

GaNs, C. (1970). Strategy and sequence in the evolution of the external gas exchangers of ectothermal vertebrates. Forma et Functio 3, 61-104.

Gans, C. (1974). Biomechanics. An Approach to Vertebrate Biology. University of Michigan Press, Ann Arbor.

GANs, C. (1985). Scenarios; why? In Evolutionary Biology of Primitive Fishes (ed. A. Gorbman, R. Olsson and R. E. Foreman), pp. I 9. Plenum Press, New York.

GaNs, C. (1987). Concluding remarks: the neural crest, a spectacular invention. In Development and Evolutionary Aspects of the Neural Crest (ed. P. F. A. Maderson), pp. 361-379. John Wiley, New York.

Gans, C. (1988). Review of R. P.S. Jefferies, The Ancestry of the Vertebrates. American Scientist 76, $188-189$.

Gans, C. \& Nonthcltt, R. G. (1983). Neural crest and the origin of vertebrates: a new head. Science, New York 220, $268-274$.

(jans, C. \& Northcutr, R. G. (1985). Neural crest: the implictions for comparative anatomy. In Functional Morphology of Vertebrates (ed. H. R. Duncker and G. Fleischer), Fortschritte Zoologie, vol. 30, pp. 507-514. Gustav Fischer Verlag, Stuttgart.

Gakstang, W. (1929). Morphology of the Tunicata and its bearing on the phylogeny of the Chordata. Quarterly Fournal of Microscopical Science N.S. 72, $51-187$.

Gaskell, W. H. (1908). The Origin of Vertebrates. Longmans, Green, London and New York.

(itrhart, J., Bi.ack, S., Scharf, S., Gimi.icj, R., Vincent, J.-P., Danilchik, M., Rowning, B. \& Roberts, J. (1986). Amphibian early development. Bioscience $36(8), 54 \mathrm{I}^{\cdots} 549$.

Gershon, M. (1987). Phenotypic expression by neural crest derived precursors of enteric neurons and glia. In Development and Evolutionary Aspects of the Neural Crest (ed. P. F. A. Maderson), pp. 181-21 1. John Wiley, New York

Gimson, R. (1972). Nemerteans. Hutchinson, London.

Gil.mour, T. H. J. (1979). Feeding in pterobranch hemichordates and the evolution of gill slits. Canadian Yournal of Zoology 57, 1136 1 142 .

Gilmour, T. H. J. (1982). Feeding in tornaria larvae and the development of gill slits in enteropneust hemichordates. Canadian Yournal of Zoology 60, 3010-3020.

Godeaux, J. E. A. (1957). Contribution à la connaissance de Thaliaces (Pyrosome et Doliolum). Embryogénèse et blastogénèse du complexe neural. Constitution et développement du stolon prolifère. Annales Société royale 7oologique Belge 88, I-285.

Godealy, J. E. A. (1974). Introduction to the morphology, phylogenesis and systematics of lower deuterostomia. In Chemical Zoology, vol. 8, pp. 3-60. Academic Press, New York.

Gore, S. C. (1979). Electron microscopic studies on differentiation of the mouse epiphyseal cartilage. Folia Biologica (Krakow) 25 (1), 8795 .

Goodrich, E. S. (1917). 'Proboscis pores' in craniate vertebrates, a suggestion concerning the premandibular somites and hypophysis. Quarterly Fournal of Microscopical Science 62, 539-55 I.

Gray, J. (1953). How Animals Move. Cambridge University Press, Cambridge.

GuThril, D. M. (1975). The physiology and structure of the nervous system of Amphioxus (the lancelet), Branchiostoma lanceolatum Pallas. Zoological Society of London Symposia (36), 4380.

(itTMANN, W. F. \& BONIK, K. (1981). Kritische Enolutionsthenrie. Ein Beitrag zur Úberwindung altdarwinistischer Dogmen. Gerstenberg, Hildesheim.

HAi., B. K. (1983). Epithelial mesenchymal interactions in cartilage and bone development. In EpithelialMesenchymal Interactions in Development (ed. R. H. Sawyer and J. F. Fallon), pp. I89-2 I4. Praeger Press, New York.

Hatstead, B. 'T. ( $(987)$. Evolutionary aspects of neural crest-derived skeletogenic cells in the earliest vertebrates. In The Neural Crest (ed. P. I. A. Maderson), pp. 339-358. John Wiley, New York.

HaRdisty, M. W. ( I 979). The Biology of Cyclostomes. Chapman and Hall, London.

Herrick, C. J. (1899). The cranial and first spinal nerves of Menidia. A contribution upon the nerve components of the bony fishes. Journal of Comparative Neurology 9, $153-455$.

II Ickman, C. P., Jr. \& 'Trump, B. F. ( I969). The kidney, In Fish Physiology, (ed. W. S. Hoar and D. J. Randall), pp. 9 I 239. Academic Press, New York.

Holmrs, W. (1953). 'The atrial nervous system of amphioxus (Branchiostoma). Quarterly Fournal of Microscopical Science 94, 523-535.

Horstadns, S. (1950). The Neural Crest: Its Properties and Derivatives in the Light of Experimental Research. Oxford University Press, Oxford. 
Hughes, G. M. (1963). Comparative Physiology of Vertebrate Respiration. Harvard University Press, Cambridge, Mass.

Hughes, G. M. (1984). General anatomy of the gills. In Fish Physiology (ed. W. S. Hoar and D. J. Randall), vol. 1o, pp. I-72. Academic Press, London.

Ivanov, A. V. (1963). Pogonophora. Consultants Bureau, New York.

IWAI, T. (1967). Structure and development of lateral line cupulae in teleost larvae. In Lateral Line Detectors (ed. P. Cahn), pp. 27-44. Indiana University Press, Bloomington.

JACOBson, A. G. (1987). Determination and morphogenesis of axial structures. In Development and Erolutionary Aspects of the Neural Crest (ed. P. F. A. Maderson), pp. 147-180. John Wiley, New York.

Jacobson, A. G. \& Meier, S. (1984). Morphogenesis of the head of a newt: mesodermal segments, neuromeres, and distribution of neural crest. Developmental Biology ro6, I $81-193$.

JÄGERsten, G. (1972). Evolution of the Metazoan Life Cycle: A Comprehensive Theory. Academic Press, New York and London.

Janvier, P. (I981). The phylogeny of the Craniata with special reference to the significance of fossil 'agnathans'. fournal of Vertebrate Paleontology I, I $2 \mathrm{I}^{-1} 59$.

JANVIER, P. \& Blieck, A. (1979). New data on the internal anatomy of the Heterostraci with general remarks on the phylogeny of the Craniotes. Zoologica Scripta 8, 287-296.

JARviK, E. (1980). Basic Structure and Evolution of Vertebrates, 2 volumes. Academic Press, London. JefFeries, R. P. S. ( 1987 ), Origin of Vertebrates. British Museum (Natural History), London.

JENSEN, D. D. ( $\mathrm{Ig63}_{3}$ ). Hoplonemertines, myxinoids, and vertebrate origins. In The Lower Metazoa: Comparatize Biology and Phylogeny (ed. E. C. Dougherty), pp. 113-126. University of California Press.

Jollie, M. (1962). Chordate Morphology. Reinhold, New York.

Jollie, M. (1971). A theory concerning the early evolution of the visceral arches. Acta Zoologica 52, 85-96.

Jollie, M. ( 1973 ). The origin of the Chordates. Acta Zoologica 52, 85-96.

Jol.tie, M. (1977). Segmentation of the vertebrate head. American Zoologist r7 (2), 323-333.

Jollie, M. (1982). What are the 'Calcichordata' and the larger question of the origin of Chordates. Zoological Fournal of the Linnean Society of London 75, $167-188$.

Just, J. J., Kraus-Just, J. \& Check, D. A. ( I981). Survey of chordate metamorphosis. In Metamorphosis. A Problem in Developmental Biology, 2nd ed. (ed. L. I. Gilberts and E. Frieden), pp. 265-326. Plenum Press, New York and London.

KalmijN, A. J. (1974). The detection of electric fields from inanimate and animate sources other than electric organs. In Electroreceptors and Other Specialized Receptors in Lower Vertebrates, vol. 3 (ed. A. Fessard), pp. I 47-200. Handbook of Sensory Physiology. Springer-Verlag, Berlin.

Katz, M. J. ( 1983 ). Comparative anatomy of the tunicate tadpole, Ciona intestinalis. Biological Bulletin $164,1-27$.

Kemp, A. (1987). Biology of the Australian lungfish, Neoceratodus forsteri (Krefft, 1870). In The Biology and Evolution of Lungfishes (ed. W. E. Bemis, W. W. Burggren and N. E. Kemp). Fournal of Morphology Supplement $I$, pp. $181-198$. Alan R. Liss, New York.

Kemp, N. E. (1984). Organic matrices and mineral crystallites in vertebrate scales, teeth and skeletons. American Zoologist 24, 965-976.

KEMP, N. E. \& WESTRIN, S. K. (1979). Ultrastructure of calcified cartilage in the endoskeletal tesserae of sharks. Fournal of Morphology 160, 75-102.

KEMP, T.S. (1982). Mammal-like Reptiles and the Origin of Mammals. Academic Press, London.

Kennedy, M. C. \& Rubinson, K. (1984). Development and structure of the lamprey optic tectum. Comparatize Neurology of the Optic Tectum (ed. H. Vanegas), pp. 1-32. Plenum Press, New York.

Kerkut, G. A. ( 1960). Implications of Evolution. Pergamon Press, Oxford.

KLuge, A. G. (1984). The relevance of parsimony to phylogenetic inference. In Cladistics: Perspectices on the Reconstruction of Evolutionary History (ed. T. Duncan and T. F. Stuessy), pp. 24-38. Columbia ('niversity Press, New York.

Kowal.ewskı, A. (1 866). Entwicklungsgeschichte der einfachen Ascidien. Mémoires d'Académie des Sciences de St Pétérsbourgh (7) ro, I-1 19.

KNight-Jones, E. W. (1952). On the nervous system of Saccoglossus cambrensis (Enteropneusta). Philosophical Transactions of the Royal Society of London B 236, $3^{1} 5-354$.

Knighr-Jones, E. W. (1953). Feeding in Saccoglossus (Enteropneusta). Proceedings of the Zoological Society of London 123, 637-654.

LAuder, G. V. ( 1983 ). Food capture. In Fish Biomechanics (ed. P. W. Webb and D. Weihs), pp. 280-311. Prager, New York.

Lauder, G. V. (1985). Functional morphology of the feeding mechanism in lower vertebrates. In Functional Morphology of Vertebrates (ed, H. R. Duncker and G. Fleischer). Fortschritte Zoologie, vol. 30, pp. 179-188. Gustav Fischer Verlag, Stuttgart. 
Laurent, P. (1984). Gill internal morphology. In Fish Physiology (ed. W. Iloar, G. M. Hughes and G. A. Sheldon), vol. 10, pp. 73-183. Academic Press, London.

LEAKE, L. D. (1975). Comparatize Histolngy. An Introduction to the Microscopic Structure of Animals. Academic Press, London.

Le Dolarin, N. (1982). The Neural Crest. Cambridge University Press, New York.

Lehman, H. E. (1977). Chordate Development, 2nd ed. Hunter Textbooks, Winston-Salem, NC.

L. Liever, C. S. \& Le Douarin, N. M. (1975). Mesenchymal derivatives of the neural crest; analysis of chimaeric quail and chick embryos. Fournal of Embryology and Experimental Morphology 34, $25-154$.

Lewis, S. V. \& PotTer, I. C. (1 982). A light and electron microscope study of the gills of larval lampreys (Geotria australis) with particular reference to the water-blood pathway. Fournal of Zoology London 198, $157-176$.

LiEM, K. F. (1985). Ventilation. In Functional Vertebrate Anatomy (ed. M. Hildebrand, D. M. Bramble, K. F. Liem and D. B. Wake), pp. ${ }_{185}$ 209. Harvard University Press, Cambridge.

Lovtku:P, S. (1977). The Phylogeny of Vertebrata. John Wilcy, New York.

Lumsden, A. G. S. (1988). Spatial organization of the epithelium and the role of neural crest cells ir the initiation of the mammalian tooth germ. In Craniofacial Development (ed. P. Thorogood and C. Tickle). Development Io3 (supplement), $155-169$.

Mallate, J. (1981). 'The suspension feeding mechanism of the larval lamprey Petromyzon marimus. Fournal of Zoology London 194, $103^{-1} 4^{2}$.

Maltatt, J. $(1984 a)$. Feeding ecology of the earliest vertebrates. Zoological fournal of the Limnean Society of London 82, 261-272.

Mal.LATT, J. ( $\left.g_{9} 8 b\right)$. Early vertebrate evolution: pharyngeal structure and the origin of gnathostomes. Yournal of Zoology, London 204, I69-183.

Mallatt, J. (1985). Reconstructing the life cycle and the feeding of ancestral vertebrates. In Evolutionary Biology of Primitive Fishes (ed. R. E. Foreman, A. Gorbman, J. M. Dodd and R. Olsson), pp. 59-68. Plenum Press, New York.

Mallatt, J. \& Paulsen, C. (1986). Gill structure of the Pacific hagfish Eptatretus stouti. American Yournal of Anatomy 177, 243-260.

MiAlester, A. L. (1968). The History of Life. Prentice Hall, Engelwood Cliffs.

Marshall, E. K., Jr. \& Smith, H. W. (1930). The glomerular development of the vertebrate kidney in relation to habitat. Biological Bulletin 59 (2), $135^{-153}$.

MeIER, S. (1979). Development of the chick embryo mesoblast: formation of the embryonic axis and the establishment of metameric pattern. Developmental Biology 73, $25 \cdots 45$.

MEIER, S. (198I). Development of the chick embryo mesoblast: morphogenesis of the prechordal plate and cranial segments. Developmental Biology 83, 49-61.

Meier, S. \& Packard JR., D. S. (1984). Morphogenesis of the cranial segments and distribution of neural crest in the embryos of the snapping turtle, Chelydra serpentina. Developmental Biology 102, 309-323.

Meinke, D. K. \& Thomson, K. S. ( $\mathrm{Ig}_{3}$ ). The distribution and significance of enamel and enameloid in the dermal skeleton of osteolepiform rhipidistian fishes. Paleobiology 9, $138-149$.

Moy-Thomas, J. A. \& Miles, R. S. (1971). Palaeozoic Fishes. W. B. Saunders, Philadelphia.

Newth, D. R. (1956). On the neural crest of the lamprey embryo. Fournal of Embryology and Experimental Morphology 4, 356-375.

Niei.sen, C. (1987). Structure and function of metazoan ciliary bands and their phylogenetic significance. Acta Zoologica $68(4), 205^{-262 .}$

Nonen, D. M. (1982). Patterns and organization of craniofacid skeletogenic and myogenic mesenchyme: a perspective. In Factors and Mechanisms Influencing Bone Growth (ed. A. Dixon and B. Sarnat), pp. I67 203. A. R. Liss, New York.

Nonen, D. M. ( $\left.\lg _{3} a\right)$. The embryonic origins of avian cephalic and cervical muscles and associated connective tissues. American fournal of Anatomy r68, 257-276.

NoDen, D. M. ( $(983 b)$. The role of neural crest in patterning of avian cranial skeletal, connective and muscle tissues. Developmental Biology 96, 144-165.

Noden, D. M. (1 984). Craniofacial development: new views on old problems. Anatomical Record $208,1-13$.

Noden, D. M. ( 1987 ). Interactions between cephalic neural crest and mesodermal populations. In The Neural Crest (ed. P. F. A. Maderson), pp. 89-1 19. John Wiley, New York.

NoDEN, D). M. (1988). Interaction and fates of avian craniofacial mesenchyme. In Craniofacial Development (ed. P. Thorogood and (. 'Tickle). Development 103 (supplement), $121-140$.

Northor,t, R. G. (1986). Embryonic origin of amphibian electroreceptors. Abstracts Society for Neuroscience 12 (r), $\mathrm{IO}_{3}$.

Nontircutt, R. G. \& Gans, C. ( $198_{3}$ ). The genesis of neural crest and epidermal placodes: a reinterpretation of vertebrate origins. Quarterly Review of Biology 58 (1), 1-28. 
NorthcutT, R. G. \& Gans, C. (1984). Vertebrata. McGraw-Hill Yearbook of Science and Technology Ig85, pp. $45^{2-455}$.

Oison, E. C. (1971). Vertebrate Paleozoology. John Wiley, New York.

Orsson, R. ( 1983 ). Club-shaped gland and endostyle in larval Branchiostoma lanceolatum (Cephalochordata). Zoomorphology 103, 1-13.

Onions, C. T. (1955). The Oxford Universal Dictionary, 3rd ed. Oxford University Press.

Orvig, T. (1972). The latero-sensory component of the dermal skeleton in lower vertebrates and its phyletic significance. Zoologica Scripta 1, 139-155.

Orvic, T. (1977). A survey of odontodes (dermal teeth) from developmental, structural, functional and phyletic points of view. In Problems in Vertebrate Evolution (ed. S. M. Andrews, R. S. Miles and A. D. Walker). Linnean Society Symposium Series 4, 53-75.

Parker, G. H. (1908). The sensory reactions of amphioxus. Proceedings of the American Academy of Arts and Sciences 43, 41 5-455.

Patten, W. (1912). The Evolution of the Vertebrates and their Kin. Blakiston, Philadephia.

Patterson, C. \& Rosen, D. E. (1977). Review of ichthyodectiform and other Mesozoic teleost fishes and the theory and practice of classifying fossils. Bulletin of the American Museum of Natural History 158, 81-172.

Pickins, P. E. (1970). Conduction along the ventral nerve cord of a hemichordate worm. Fournal of Experimental Biology 52, 51 5-528.

Prosser, C. L. (ed.) (1958). Physiological Adaptation. American Physiological Society, Washington, D.C.

Prosser, C. L. (ed.) ( 1980 ). Comparative Animal Physiology, 3 rd ed. Saunders, Philadelphia.

Prostak, K. \& Sкове, Z. (1986). Ultrastructure of the dental epithelium and odontoblasts during enameloid matrix deposition in cichlid teeth. Fournal of Morphology 187, 159-172.

RäHR, H. ( $198 \mathrm{I}$ ). The ultrastructure of the blood vessels of Branchiostoma lanceolatum (Pallas) (Cephalochordata). I. Relations between blood vessels, epithelia, basal laminae, and 'connective tissue'. Zoomorphology 97, 53-74.

REIF, W.-E. ( 1982 ). Evolution of dermal skeleton and dentition in vertebrates : the odontode regulation theory. In Evolutionary Biology, vol. I 5 (ed. M. K. Hecht, B. Wallace and G. T. Prance), pp. 287-368. Plenum Press, New York and London.

RiEgel, J. A. (1986). Hydrostatic pressures in glomeruli and renal vasculature of the hagfish, Eptatretus stouti. Journal of Experimental Biology 123, 359-371.

Roberts, T. D. M. (1950). The respiratory movements of the lamprey (Lampetra fluviatilis). Proceedings of the Royal Society of Edinburgh B 64, 235-252.

Romer, A. S. (1933). Eurypterid influence on vertebrate history. Science, New York 78, II4-II7.

Romer, A. S. (1962). The Vertebrate Body, 3rd ed. W. B. Saunders, Philadelphia.

Romer, A.S. (1966). Vertebrate Paleontology, 3rd ed. University of Chicago Press.

Romer, A. S. (1972). The vertebrate as a dual animal - somatic and visceral. Evolutionary Biology 6, I $21-156$.

Rovainen, C. M. \& Schieber, M. H. (1975). Ventilation of larval lampreys. Fournal of Comparative Physiology 104, $185-203$.

Ruben, J. A. \& Bennett, A. F. (1980). Antiquity of the vertebrate pattern of activity metabolism and its possible relation to vertebrate origins. Nature (London) $\mathbf{2 8 6}, 886-888$.

Ruben, J. A. \& Bennett, A. F. (I98I). Intense exercise, bone structure and blood calcium levels in vertebrates. Nature (London) 291, $411 \div 413$.

Rubinson, K., Ripps, H., Witkovsky, P. \& Kennedy, M. C. (r977). Retinal development in the lamprey, Petromyzon marinus. Abstracts, Society for Neuroscience 3, 575.

Russel.L, D. F. (1983a). Is there an inhibitory phase during the respiratory thythm of lampreys? Journeaux Thematiques I.N.P. Locomotion. Approaches Interdisciplinaires, p. 36 . CNRS, Marseille.

Russelt, D. F. ( $\mathrm{g}_{93} b$ ). Is lamprey respiration a one-phase rhythm? Abstracts, Society for Neuroscience 9, 753.

Schaeffer, B. (1977). The dermal skeleton in fishes. In Problems in Vertebrate Evolution (ed. S. M. Andrews, R. S. Miles and A. D. Walker). Linnean Society Symposium Series 4, $25^{-52 .}$

Schaeffer, B. \& Thomson, K. S. (1980). Reflections on agnathan gnathostome relationships. In Aspects of Vertebrate History : Essays in Honor of Edwin Harris Colbert (ed. L. L. Jacobs), pp. 19-33. Museum of Northern Arizona Press, Flagstaff,

Schmidt-Niel.SEn, K. (1984). Scaling: Why is Animal Size so Important? Cambridge University Press, Cambridge.

Schulte, E. \& Riehi, R. ( 1977). Elektronenmikroskopische Untersuchungen an den Oralcirren und der Haut von Branchiostoma lanceolatum. Helgoländer wissenschaftliche Meeresuntersuchungen 29, 337-357.

Si.avkin, H. C., Graham, E., Zeichiner-David, M. \& Hildemann, W. (ig83). Enamel-like antigens in hagfish: Possible evolutionary significance. E2olution 37 (2), 404-412.

Solthwakd, E. C. (1975). Fine structure and phylogeny of the Pogonophora. Zoological Society of London Symposia (36), 235-251. 
Sremann, H. (1936). Experimentelle Beiträge zu einer Theorie der Entwicklung. Julius Springer Verlag, Berlin.

Sipemann, H. ( 1938 ). Embryonic Development and Induction. Yale University Press, New Haven. (Reprint 1962 ; llafner, New York).

STARCk, 1). (1978). Vergleichende Anatomie der Wirbeltiere auf evolutionsbiologischer Grundlage. I. Theoretische Grundlage. Stammesgeschichte und Systematik unter Berücksichtigung der niederen Chordata. Springer-Verlag, Berlin.

STrfssio, E. A. (1927). The Downtonian and Devonian vertebrates of Spitsbergen. 1. Family Cephalaspidae. Skrifter Szalbard Ishavet (12), $139 \mathrm{I}$.

Strinsiö, E. (1968). The cyclostomes with special reference to the diphyletic origin of the Petromyzontida and Myxinoidea. In Nobel Symposium 4 (ed. T. Orvig), pp. 13-71. Almqvist and Wiksell, Stockholm.

StrathmanN, R. R. (1982). Comment on Dr Gilmour's views on feeding by hemichordates and lophophorates. Canadian Yournal of Zoology 6o, 3466-3468.

Taylor, 'T. N. (1981). Paleobotany. An Introduction to Fossil Plant Biology. McGraw-Hill, New York.

'I'Hompson, K. S. (1977). On the individual history of cosmine and possible electroreceptive functions of the porecanal system in fossil fishes. In Problems in Vertebrate Evolution (ed. S. Mahala Andrews, R. S. Miles and A. D. Walker). Linnean Society Symposium Series 4, $24727^{\circ}$.

van Wijhe, J. W. ( I 914$)$. On the metamorphosis of Amphioxus lanceolatus. Proceedings van de Koninglijk Akademie ran Wetenschappen Amsterdam 16, 574-583.

Vinninkov, Y. A. ( 1982$)$. Evolution of receptor cells. Molecular Biology, Biochemistry and Biophysics 34, 1”141.

Wachtifr, F., Jacob, H. J., Jасов, M. \& Christ, B. ( 1984 ). The extrinsic ocular muscles in birds are derived from the prechordal plate. Naturvissenschaften 71, 379-380.

WAinurioht, S. A. (ro 83 ). 'To bend a fish. In Fish Biomechanics (ed. P. W. Webb and D. Weihs), pp. 68.91. Prager, New York.

WatTs, D. C. (1975). Evolution of phosphate kinases in the chordate line. Zoological Society of London Symposia (36), $105^{-127}$

WLBs, J. E. (1969). On the feeding and behavior of the larva of Branchiostoma lanceolatum. Marine Biology 3 , $58-72$

WLHB, J. E. (1973). The role of the notochord in forwards and reverse swimming and burrowing in the amphioxus, Branchinstoma lanceolatum. Fournal of Zoology London $\mathbf{1 7 0}, 32533^{8}$.

WEBв, J. E. (1975). The distribution of amphioxus. Zoological Society of London Symposia 36, 179212.

Wenn, P. W. (1975). Hydrodynamics and energetics of fish propulsion. Fisheries Research Baard of Canada, Bulletin 190, 159 pp.

Weis, P. W. (1978). Fast-start performance and body form in seven species of teleost fish. Fournal of Experimental Biology 74, 157-177.

WEBr, J. E. \& HILI, M. B. (1958). 'The ecology of Lagos lagoon. IV. On the reactions of Branchiostoma nigeriense Webb to its environment. Philosophical Transactions of the Royal Society of London B 24r, 355-39I.

Wem, P. W. \& Wins, D. (1986). Functional locomotor morphology of early life history stages of fishes. Transactions of the American Fisheries Society $115,15-127$.

Wel..s, R. M. G., Fonster, M. E., Davison, W., Taylor, H. H., Davie, D. S. \& Satchiel, G. H. (rg86). Blood oxygen transport in the free-swimming hagfish, Eptatretus cirrhatus. Fournal of Experimental Biology 123, 43-53.

Wésch, [1. (1975). The fine structure of the pharynx, cyrtopodocytes and digestive caecum of amphioxus (Branchiostoma lanceolatum). Zoological Society of London Symposia 36, 17-41.

Whitear, M. (1957). Some remarks on the ascidian affinities of vertebrates. Annals and Magazine of Natural History (12) ro, $33^{8-347 .}$

Whiting, H. P. \& Bone, Q. (1980). Ciliary cells in the epidermis of the larval Australian dipnoan, Neoceratodus. Fournal of the Linnean Society of London 68, $125^{-1} 37$.

Whicer, A. (1891). Later larval development of Amphioxus. Quarterly fournal of Microscopical Science 32, ${ }_{1} 83^{-2}-24$.

Will.ey, A. (1894). Amphioxus and the Ancestry of Vertebrates. Columbia University, Biol. Ser., 2. Macmillan, New York and London.

Willmer, E. N. (1974). Nemertines as possible ancestors of the vertebrates. Biological Reviews $49,321-363$.

WIIIMER, E. N. (1975). The possible contribution of the nermertines to the problem of the phylogeny of the protochordates. Zoological Society of London Symposia (36), 319*345.

YALDEN, D. W. ( $9^{98}$ ). Feeding mechanisms as evidence for cyclostome monophyly. Zoological fournal of the Linnean Society of London $84,291-300$.

Young, J. Z. (1981). The Life of Vertebrates, 3rd ed. Clarendon Press, Oxford. 